OPEN ACCESS

Edited by:

Juan Sanjuan,

Estación Experimental de Zaidín,

Consejo Superior de Investigaciones

Cientificas (CSIC), Spain

Reviewed by:

Monika Janczarek,

Marie Curie-Skłodowska University,

Poland

Antonio Lagares,

Universidad Nacional de La Plata,

Argentina

Anibal Roberto Lodeiro, CONICET Instituto de Biotecnologia y Biologia Molecular (IBBM), Argentina

${ }^{*}$ Correspondence:

Carmen Sánchez-Cañizares

carmen.sanchez-canizares@

plants.ox.ac.uk

tORCID:

Marcela Mendoza-Suárez orcid.org/0000-0003-3419-1362

Stig U. Andersen orcid.org/0000-0002-1096-1468

Philip S. Poole orcid.org/0000-0001-5087-6455

Carmen Sánchez-Cañizares orcid.org/0000-0003-4620-5274

Specialty section:

This article was submitted to Plant Symbiotic Interactions,

a section of the journal

Frontiers in Plant Science

Received: 03 April 2021

Accepted: 19 July 2021

Published: 19 August 2021

Citation:

Mendoza-Suárez M,

Andersen SU, Poole PS and

Sánchez-Cañizares C (2021)

Competition, Nodule Occupancy, and Persistence of Inoculant Strains: Key Factors in the Rhizobium-Legume

Symbioses

Front. Plant Sci. 12:690567. doi: 10.3389/fp/s.2021.690567

\section{Competition, Nodule Occupancy, and Persistence of Inoculant Strains: Key Factors in the Rhizobium-Legume Symbioses}

\author{
Marcela Mendoza-Suárez ${ }^{1+}$, Stig U. Andersen ${ }^{1 \dagger}$, Philip S. Poole ${ }^{2 \dagger}$ and \\ Carmen Sánchez-Cañizares ${ }^{2 *}$ \\ ${ }^{1}$ Department of Molecular Biology and Genetics, Aarhus University, Aarhus, Denmark, ${ }^{2}$ Department of Plant Sciences, \\ University of Oxford, Oxford, United Kingdom
}

Biological nitrogen fixation by Rhizobium-legume symbioses represents an environmentally friendly and inexpensive alternative to the use of chemical nitrogen fertilizers in legume crops. Rhizobial inoculants, applied frequently as biofertilizers, play an important role in sustainable agriculture. However, inoculants often fail to compete for nodule occupancy against native rhizobia with inferior nitrogen-fixing abilities, resulting in low yields. Strains with excellent performance under controlled conditions are typically selected as inoculants, but the rates of nodule occupancy compared to native strains are rarely investigated. Lack of persistence in the field after agricultural cycles, usually due to the transfer of symbiotic genes from the inoculant strain to naturalized populations, also limits the suitability of commercial inoculants. When rhizobial inoculants are based on native strains with a high nitrogen fixation ability, they often have superior performance in the field due to their genetic adaptations to the local environment. Therefore, knowledge from laboratory studies assessing competition and understanding how diverse strains of rhizobia behave, together with assays done under field conditions, may allow us to exploit the effectiveness of native populations selected as elite strains and to breed specific host cultivar-rhizobial strain combinations. Here, we review current knowledge at the molecular level on competition for nodulation and the advances in molecular tools for assessing competitiveness. We then describe ongoing approaches for inoculant development based on native strains and emphasize future perspectives and applications using a multidisciplinary approach to ensure optimal performance of both symbiotic partners.

Keywords: bioinoculants, biofertilizers, competition, rhizobia, sustainable agriculture, symbiosis, biological nitrogen fixation, legume

\section{INTRODUCTION}

Biological nitrogen fixation (BNF) is an important source of nitrogen, and the various legume crops and pasture species often fix as much as 200 to $300 \mathrm{~kg}$ of nitrogen per hectare per year (Peoples et al., 1995). Altogether, the legume-Rhizobium symbioses contribute the equivalent of approximately a quarter of the nitrogen applied to arable land annually as chemical fertilizers 
(Herridge et al., 2008). The use of legumes in rotations also offers control of crop diseases and pests (Graham and Vance, 2000). The benefits of the symbioses between legumes and nitrogen-fixing bacteria are crucial in farming systems worldwide. Rhizobia are ubiquitous in soil but show great variation in their number and composition of natural populations depending on properties of the soils (Brockwell et al., 1995; Hirsch, 1996; Vuong et al., 2017). Their ability to form nodules in the presence of other strains determines their nodulation competitiveness (referred to here as rhizobial competitiveness; Yates et al., 2011; Onishchuk et al., 2017). While nitrogen fixation in an inoculated pasture is assumed to be due to the strain used in the inoculant, the identity of the strains occupying the nodules is generally unknown (Irisarri et al., 2019). Several rhizobia strains can inhabit nodules within the same host plant, even co-inhabiting the same nodule (Mendoza-Suárez et al., 2020), and compete for host resources with non-fixing ("cheating") strains (Checcucci et al., 2017). However, it has been shown that plants can sanction nodules that are inefficient at fixing nitrogen (Kiers et al., 2003; Regus et al., 2017; Westhoek et al., 2021). Moreover, legumes are able to control the number of nodules formed through an "autoregulation" process in which a shoot-derived signal limits infection (Kinkema et al., 2006; Ferguson et al., 2010; Reid et al., 2011; Mortier et al., 2012). The phytohormone ethylene also has an inhibitory effect on nodulation in most legumes (Penmetsa and Cook, 1997; Penmetsa et al., 2003; Lin et al., 2020), although rhizobia can influence these mechanisms by altering ethylene levels via the production of a rhizobiotoxine which inhibits ethylene biosynthesis of host roots (Ma et al., 2002; Sugawara et al., 2006).

Rhizobial competitiveness has important practical implications for agriculture, as differences in nitrogen fixation efficiency between strains can be large (Slattery and Pearce, 2002; Irisarri et al., 2019). Elite rhizobial inoculants must be highly effective in providing the plant with fixed nitrogen $\left(\mathrm{N}_{2}\right.$ effectiveness) and, at the same time, be highly competitive for nodule occupancy (competitiveness) in a background of native rhizobia that may show high competitiveness combined with low $\mathrm{N}_{2}$-effectiveness (Checcucci et al., 2017; Onishchuk et al., 2017).

Microbial interactions in agriculture are part of a multicomponent equation that includes (i) plant genotype, (ii) environment, and (iii) plant and soil microbiomes. These factors should be taken into account when evaluating the success of beneficial microbes (Sessitsch et al., 2002; Busby et al., 2017; Onishchuk et al., 2017; diCenzo et al., 2019). Nodule formation, and therefore rhizobial competitiveness, is affected by soil type and its physicochemical properties (i.e., temperature, $\mathrm{pH}$, and moisture; Hungria and Franco, 1993; Frey and Blum, 1994; Anyango et al., 1995; Montañez et al., 1995; Zahran, 1999; Rao et al., 2002; Rathi et al., 2018), nutrient availability and the ability of microbes to use them (Rynne et al., 1994; Kyei-Boahen et al., 2017; Kasper et al., 2019), the population of native rhizobia and the remaining soil microbiome (Meade et al., 1985; Siefert et al., 2018; Han et al., 2020), previous inoculation history (Laguerre et al., 2003; Batista et al., 2015), and/or the choice of inoculation method (Danso and Bowen, 1989; López-García et al., 2009). The degree to which the rhizobial strains adapt to the local soil conditions will strongly influence the competition between strains.

But how is this endosymbiotic relationship with legumes established? Nitrogen-fixing rhizobia have complex life cycles (Poole et al., 2018). Rhizobia are found as free-living bacteria in soil and in the rhizosphere, which are highly heterogeneous environments in both space and time. In brief, the symbiosis is initiated in the rhizosphere following an exchange of signals between both partners (Oldroyd and Downie, 2004; Oldroyd et al., 2011; Udvardi and Poole, 2013; Figure 1A). Root exudates released into the rhizosphere are also part of this chemical dialogue (Badri and Vivanco, 2009), being specific for the plant genotype (Monchgesang et al., 2016) and changing during the life cycle of the plant, the root zone, the rhizosphere microbial community and with time (Zhalnina et al., 2018; Canarini et al., 2019; Korenblum et al., 2020). In nature, host legumes are surrounded by other plants, and other roots or mesofauna may also exude chemoattractants, adding noise to the host root exudate (De-la-Peña et al., 2008). Therefore, bacterial attraction and initial root colonization occurs at multiple stages that are defined by spatial and temporal separation (Massalha et al., 2017; Poole, 2017). Indeed, a microfluidicsbased approach combined with advanced microscopy showed that the first step in colonization seems to involve newly divided and undifferentiated cells in the nutrient-rich microenvironment of the root elongation zone (Massalha et al., 2017). Bacterial accumulation at this site occurs prior to the attachment to differentiated root-hair cells (Massalha et al., 2017; Poole, 2017). They usually adhere to roots using adsorption, root attachment being affected by soil and root physicochemical properties, such as $\mathrm{pH}, \mathrm{Ca}^{2+}$ and $\mathrm{Mg}^{2+}$ concentrations and water availability (Rodríguez-Navarro et al., 2007).

The infection process starts when rhizobia enter root systems through natural cracks between epidermal cells at the base of emerging lateral roots (termed "crack entry"), or, more commonly, when compatible rhizobia induce curling and deformation of growing root hairs around the bacterial cells that subsequently enter through an intracellular infection thread (IT, Figure 1A; Rae et al., 2021). Crack entry infection is considered more primitive than ITs because the host does not experience sophisticated cellular differentiation of root hairs (Sprent, 2008; Gage, 2019), although some species of plants (e.g., Lotus japonicus) can alter their mode of infection depending on the site of infection (Montiel et al., 2021). Only the emerging root hairs are infectable, with polar root hair growth required to achieve the necessary root hair deformation and cell wall invagination to form an IT (Turgeon and Bauer, 1985; Esseling et al., 2003). Hence, this process is a transient phenomenon, as root hairs remain infectable for only a few hours in a given root region. Whereas the transiency of root hair infectability highlights the relevance of the reversible and generally polar attachment to emerging root hairs, the irreversible attachment and biofilm formation seems relevant for rhizosphere and soil colonization, although not for infection and nodulation, as it would be completed only after the root hairs are no longer infectable. IT initiation and elongation continues through cortical cell layers until rhizobia are released into dividing 


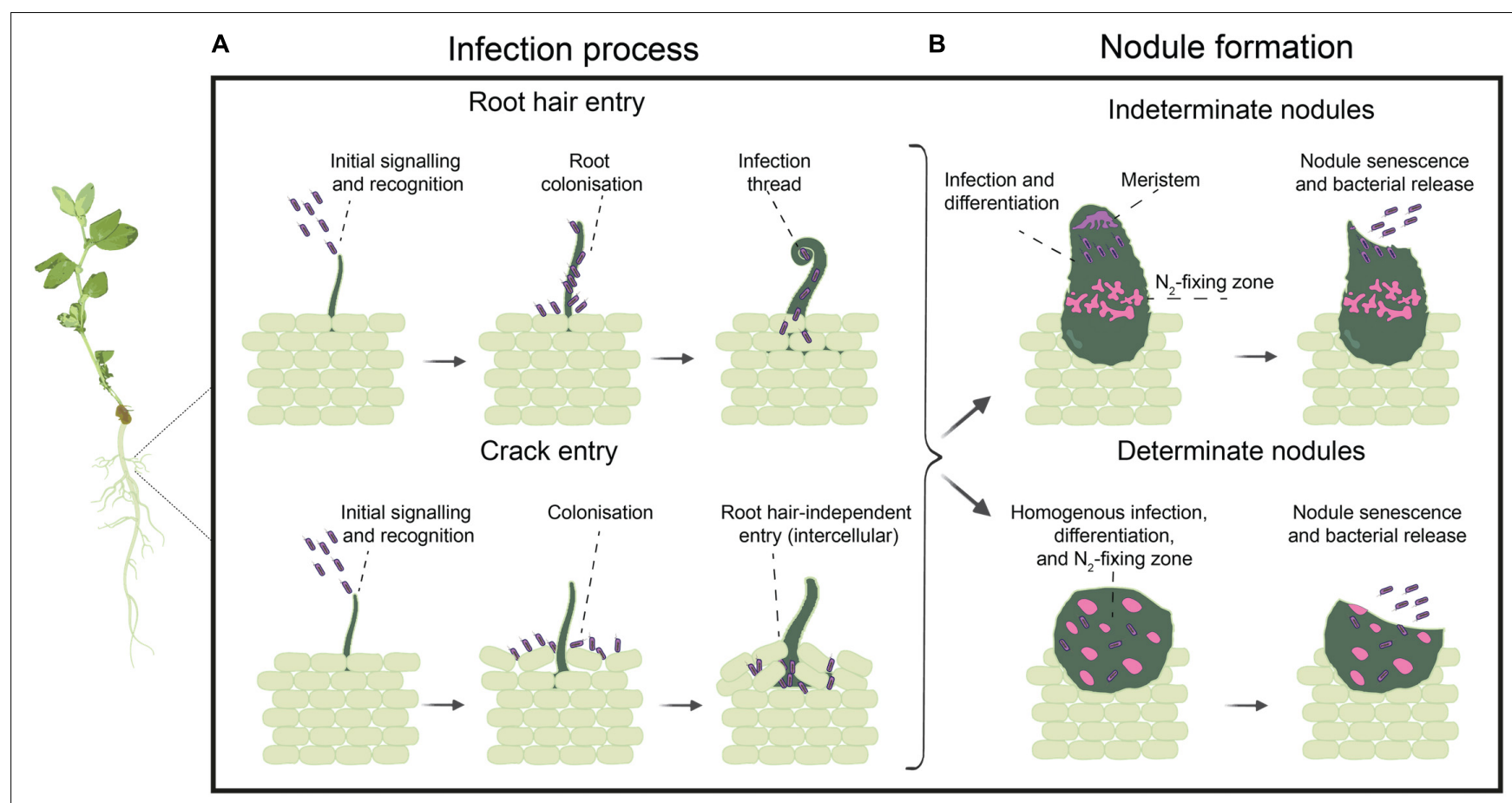

FIGURE 1 | Infection process and nodule formation. (A) Infection process steps taking place in the case of root hair entry, with root colonization followed by root hair curling and intracellular invasion by the formation of infection threads (ITs), or crack entry, with colonization occurring between root epidermal cells followed by intercellular root cortical cells invasion of free-living cells (in purple). (B) Nodule formation and bacteroid differentiation (larger, pink cells), with a defined spatial distribution in the case of indeterminate nodules, harboring undifferentiated cells in the nodule meristem and differentiated and branched bacteroids in the nitrogen-fixing zone, versus and homogenous infection zone in the determinate nodules, harboring both non-differentiated cells and rounded and differentiated bacteroids together. Once the nodule senesces, the bacterial cells are released back into the soil.

cortical cells. They are taken up into the plant cytosol and surrounded by a plant-derived membrane (Figure 1B). The rhizobial cells with their plant surrounding membrane are known as symbiosomes, which are temporary plant organelles where nitrogen fixation takes place (Gage, 2019; Pérez-Giménez et al., 2021). In the symbiosomes, rhizobia adjust their metabolism in response to the stress conditions, differentiating into bacteroids, after which the nitrogenase complex is expressed, leading to active $\mathrm{N}_{2}$-fixation (Poole et al., 2018; Ledermann et al., 2021). There is no general consensus on the morphological types of legume nodules and their internal structure. Although some authors use a classification system with up to five nodule types - aeschynomenoid, desmodioid, indeterminate, lupinoid, and primitive (Sprent, 2008) - the major types of nodule shape and structure are determinate and indeterminate nodules (Figure 1B). Determinate nodules are spherical, lacking a persistent meristem and therefore cease growing at some point, whereas indeterminate nodules are elongated, with a persistent meristem, resulting in indefinite growth and branching in irregular shapes (Ferguson et al., 2010). These two patterns of nodule development differ also in bacteroid differentiation, with determinate nodules showing a more synchronic, timedependent and homogeneous maturation of most rhizobia within the nodules, in contrast to indeterminate nodules, in which rhizobia at different stages of differentiation are observed within the same nodule, with bacteroid maturation depending on the different nodule spatial zones (Ferguson et al., 2010; Poole et al., 2018). Bacteroids in determinate nodules are viable and retain their morphology and their capacity to divide and revert to free-living cells, whereas in indeterminate nodules, only a small fraction of rhizobial cells in the saprophytic zone of nodules remains in a viable and vegetative form, being able to multiply in the infection threads and regrow outside the nodule, increasing the bacterial population in the soil after nodule senescence (Mergaert et al., 2006; Montiel et al., 2017). When the nodule senesces, the saprophytic zone that is formed is where rhizobia are nourished by the products of organic breakdown and decay and multiply massively (Timmers et al., 2000; Wielbo et al., 2010). What we do not yet understand is which phases in the nodulation process are exposed to competition.

The improvement of symbiotic nitrogen fixation is one of the main challenges facing agricultural research. It is therefore necessary to evaluate nodule occupancy in order to assess the competitiveness of a strain. Although competition assays must include field assessments that confirm the results obtained from experiments under controlled conditions, there are limitations when they are performed at a large scale. Here, we will review the molecular factors that can influence rhizobial competitiveness and how the development of molecular tools is simplifying this task and we will discuss the implications of rhizobial competitiveness for the establishment of a successful symbiosis and for the search for elite rhizobial strains. We will also 
emphasize the importance of performing $\mathrm{N}_{2}$-effectiveness and competitiveness assays using relevant field soils and plant genotypes. Although crop management and environmental factors (for example: soil $\mathrm{pH}$, soil temperature, salinity, moisture, soil texture, among others) are not discussed in this review, these factors can also influence rhizobial competitiveness and, therefore, future inoculant performance (reviewed in detail by Vlassak and Vanderleyden, 1997; Saad et al., 2020).

\section{TYPES OF COMPETITION AND GENETIC FEATURES INFLUENCING COMPETITIVENESS}

Competition for nodulation is a key adaptive feature of rhizobia that is of great importance in the practical application of inoculants. However, the genetic basis of competitiveness for nodule formation is not fully understood yet. What we know is that competitiveness, similarly to nitrogen fixation, is controlled by specific genes that are expressed during different time points in nodule development (Ampe et al., 2003; Barnett et al., 2004). In addition, rhizobia are part of the plant microbiome community and, as such, they have to interact with the nonrhizobial accompanying members of this dynamic community in order to undertake a range of beneficial functions including growth promotion, nutrient acquisition, pathogen resistance or stress tolerance, thus, exploiting the versatile benefits offered by plant-microbe interactions (as reviewed by Compant et al., 2019; Trivedi et al., 2020). The assemblage of the plant microbiome community is currently the focus of active investigation, as different components have been shown to have a crucial impact in the assembly process, such as the soil and seed-born initial microbial repertoires, both accounting for key microbemicrobe interactions within this microbial consortium (Philippot et al., 2013; Turner et al., 2013; Zgadzaj et al., 2016; Nelson, 2018). Indeed, Plant Growth-Promoting Rhizobacteria (PGPR) have been found to be enriched in the soybean rhizosphere, reinforcing the idea that rhizosphere recruitment is an important first step in symbiotic interactions (Liu et al., 2019). Hence, elite inoculant behaviors appear to be a consequence of gene assortment, with genes involved in an efficient symbiosis with their plant hosts, PGPR traits, or secretion systems (PastorBueis et al., 2019). Onishchuk et al. (2017) identified two types of competition influenced by different factors: exploitative (indirect) competition, involving a more effective use of a common limiting nutrient, or interference (direct) competition, whereby other cells are prevented from growing and surviving in the environment. Hence, to be both competitive and $\mathrm{N}_{2}$ effective, an elite strain should have genetic components that enable it to (i) successfully colonize the rhizosphere and benefit from available nutrients in an effective way, (ii) prevent the growth of other bacterial cells, (iii) establish an efficient symbiosis, and (iv) promote plant growth. Here, we will review some of the components that are relevant to the four points mentioned above and summarized in Table 1. The genetic knowledge on the pre-infection, infection and nodulation stages has mainly been gained from experiments with defective mutants and, more recently, with high-throughput technologies. Hence, although these data come from laboratory experiments, such traits may also be present in the soil rhizobia populations. Manipulating the expression of these traits, either genetically or through culture conditions, may lead to improvements in the ability of rhizobial strains to compete against endogenous soil populations.

\section{Genetic Components for Rhizosphere Colonization}

When it comes to exploitative competition, where bacteria compete for the same common resources without directly interacting, bacterial chemotaxis toward exuded compounds is an important trait for root colonization and plant-driven selection of microorganisms (Bais et al., 2006; Raina et al., 2019). Motility and chemotaxis are factors affecting nodulation efficiency and competitiveness (Mellor et al., 1987; Caetano-Anollés et al., 1988; Bauer and Caetano-Anollés, 1990). Disruption of the flagellum hook gene flgE in Mesorhizobium tianshanense caused a flagellarless phenotype, leading to the complete loss of swimming ability, a heavier biofilm formation and decreased bacterial attachment on the root hair. These in vitro assays suggest that flagella are involved in the early stage of the symbiosis process (Zheng et al., 2015). The major chemotaxis gene cluster of Rhizobium leguminosarum bv. viciae, Che1, has been shown to be essential for competitive nodulation (Miller et al., 2007; Wheatley et al., 2020). It has to be noted that these observations have been mainly made from laboratory experiments carried out either in liquid media or in flooded substrates and cannot be extrapolated to soil conditions (Iturralde et al., 2019). Motility of inoculated rhizobia in soils at field-capacity is generally scarce; therefore, the distribution of the rhizobia in the soil profile is important, as it facilitates entry of growing roots in contact with the static rhizobia (López-García et al., 2002, 2009). Motility and chemotaxis might only have an effect during the short periods of rainfall or watering, during which the soil pores are water-saturated. Consequently, inoculant competitiveness may be improved through the application of liquid in-furrow inoculants, contributing to rhizobial dispersion, instead of seedcoated dried inoculation.

In the case of root colonization patterns, PGPR share common mechanisms with rhizobia for colonizing roots (Drogue et al., 2012). Attachment of bacteria to root surfaces is a multi-step process. An initial reversible attachment is followed by an irreversible attachment that occurs several hours after initial attachment, and, finally, biofilms can form over a few days (Dazzo et al., 1984; Smit et al., 1992). Two adhesion mechanisms have been described in $R$. leguminosarum to mediate the reversible and polar attachment to root hairs depending on the soil $\mathrm{pH}$ : in acidic conditions, rhizobial surface polysaccharide glucomannan binds to plant lectin, expressed on root-hair tips (Laus et al., 2006; Williams et al., 2008). Whereas under neutral or alkaline conditions, root lectins are solubilised and rhicadhesin, a hitherto unidentified calciumbinding protein, was proposed long ago to facilitate attachment to root hairs (Smit et al., 1989), although the gene encoding it 
TABLE 1 | Examples of some of the genes reported to be involved in competition.

\begin{tabular}{|c|c|c|c|c|}
\hline Category & Gene function & Gene name & Rhizobial strain object of the study & Publication \\
\hline & $\mathrm{ABC}$ transporters & $\begin{array}{l}\text { teuBAC1C2 (root exudates) } \\
\text { aapJQMP (branched-chain amino } \\
\text { acids) } \\
\text { livM (branched-chain amino acids) }\end{array}$ & $\begin{array}{l}\text { R. tropici CFN299 } \\
\text { R. leguminosarum } \\
\text { E. meliloti } 2011\end{array}$ & $\begin{array}{l}\text { Rosenblueth et al., } 1998 \\
\text { Green et al., } 2019 \\
\text { Pobigaylo et al., 2008* }\end{array}$ \\
\hline & EPS biosynthesis & $\begin{array}{l}\text { dgoK } \\
\text { pssA }\end{array}$ & $\begin{array}{l}\text { E. meliloti } \\
\text { R. leguminosarum bv. trifolii }\end{array}$ & $\begin{array}{l}\text { Geddes et al., } 2014 \\
\text { Janczarek et al., } 2009\end{array}$ \\
\hline & & pssD & R. leguminosarum bv. viciae 3841 & Wheatley et al., $2020^{*}$ \\
\hline & & exoY & S. meliloti 1021 & Jones, 2012 \\
\hline & $\begin{array}{l}\text { Lypopolysaccharide } \\
\text { biosynthesis }\end{array}$ & $\begin{array}{l}\operatorname{lpsB} \\
\operatorname{acpXL}\end{array}$ & E. meliloti 2011/1021 & $\begin{array}{l}\text { Niehaus et al., 1998; Lagares } \\
\text { et al., 1992; Campbell et al., } \\
\text { 2002; Sharypova et al., } 2003\end{array}$ \\
\hline & $\begin{array}{l}\text { PHB synthesis and } \\
\text { degradation }\end{array}$ & $\begin{array}{l}\text { phaC } \\
\text { bdhA }\end{array}$ & E. meliloti & Aneja et al., 2005 \\
\hline & Homoserine catabolism & pRL80079-pRL80088 & R. leguminosarum bv. viciae 3841 & Vanderlinde et al., 2014 \\
\hline & Proline catabolism & proDH & E. meliloti GRM8 & Jimenez-Zurdo et al., 1995 \\
\hline & Rhamnose catabolism & rhaRSTPQUK, rhaDI & R. leguminosarum bv. trifolii Rlt100 & Oresnik et al., 1998 \\
\hline & Myo-inositol catabolism & $\begin{array}{l}\text { iolDEB } \\
\text { iolA, iolRCDEB }\end{array}$ & $\begin{array}{l}\text { R. leguminosarum } \\
\text { E. meliloti } 2011\end{array}$ & $\begin{array}{l}\text { Fry et al., } 2001 \\
\text { Pobigaylo et al., 2008*; Kohler } \\
\text { et al., } 2010\end{array}$ \\
\hline & Glycerol catabolism & gIpDSTPQUVK & R. leguminosarum bv. viciae VF39 & Ding et al., 2012 \\
\hline & Transcriptional regulation & $\begin{array}{l}\text { rsh } \\
\text { rosR }\end{array}$ & $\begin{array}{l}\text { B. diazoefficiens USDA } 110 \\
\text { R. etli CE3 } \\
\text { R. leguminosarum bv. trifolii } 24.2\end{array}$ & $\begin{array}{l}\text { Pérez-Giménez et al., } 2021 \\
\text { Bittinger et al., } 1997 \\
\text { Janczarek et al., 2010; } \\
\text { Rachwał et al., } 2016\end{array}$ \\
\hline & $\begin{array}{l}\text { Type IV secretion system - } \\
\text { pilus (T4SS) }\end{array}$ & virB1-virB11 & S. meliloti & Nelson et al., 2017 \\
\hline & $\begin{array}{l}\text { Type VI secretion system } \\
\text { (T6SS) }\end{array}$ & $\begin{array}{l}\text { tssHD } \\
\text { tsSABC1C2 } \\
\operatorname{tagH} \\
\text { tssEFGGHKLMFE }\end{array}$ & R. etli Mim1 & Salinero-Lanzarote et al., 2019 \\
\hline $\begin{array}{l}\text { (iii) Genetic } \\
\text { components to } \\
\text { establish an efficient } \\
\text { symbiosis }\end{array}$ & Nodulation & nodD & $\begin{array}{l}\text { R. tropici strain CIAT } 899 \\
\text { R. leguminosarum bv. trifolii }\end{array}$ & $\begin{array}{l}\text { del Cerro et al., } 2015 \\
\text { Ferguson et al., } 2020\end{array}$ \\
\hline \multirow{4}{*}{$\begin{array}{l}\text { (iv) Genetic } \\
\text { components to } \\
\text { promote plant growth }\end{array}$} & $\begin{array}{l}\text { Tryptophan biosynthesis } \\
\text { (precursor of IAA and auxin) }\end{array}$ & $\begin{array}{l}\operatorname{trp} E F \\
\operatorname{trpC} \operatorname{trp} F\end{array}$ & E. meliloti 2011 & $\begin{array}{l}\text { Barsomian et al., } 1992 \\
\text { Pobigaylo et al., } 2008^{\star}\end{array}$ \\
\hline & & $\operatorname{trp} B$ & R. etli CE3 & Taté et al., 1999 \\
\hline & Phosphate solubilization & $\begin{array}{l}\text { phoR, phoUB } \\
\text { ptsSCAB }\end{array}$ & E. meliloti 2011 & Pobigaylo et al., 2008* \\
\hline & $\begin{array}{l}\text { Siderophore production } \\
\text { (Rhizobactin 1021) }\end{array}$ & $\begin{array}{l}r h b A B C D E F \\
r h t A, r h r A\end{array}$ & E. meliloti 1021 & Lynch et al., 2001 \\
\hline
\end{tabular}

${ }^{*}$ Studies with several other genes reported to affect competition, but not all included in this table. 
is still a mystery. When competing with the wild type during nodule infection, the glucomannan mutant ( $g m s A)$ was strongly outcompeted (Williams et al., 2008). There are also other plant components influencing the attachment of $R$. leguminosarum to surfaces such as an arabinogalactan protein (Xie et al., 2012). Weak adherence and reversible attachment are mediated mainly by proteins and anchoring, while stronger adherence and irreversible attachment is mediated by polysaccharides (reviewed by Wheatley and Poole, 2018). Rhizobial adhering proteins (Raps) promote attachment and aggregation by rhizobia (Ausmees et al., 2001). Mutation of the transcriptional regulator praR, modulating the expression of the genes encoding Raps, results in enhanced in vitro biofilm formation, attachment to root hairs and increased nodulation competitiveness primarily due to the enhanced expression of Rap proteins (Frederix et al., 2014). Cyclic glucans (CG), exopolysaccharides (EPS), lipopolysaccharides (LPS), and capsular polysaccharides (KPS) are the main rhizobial surface polymers required for successful nodulation (Margaret et al., 2011). EPS is an extracellular carbon polymer weakly associated with the bacterial surface and thus abundantly released into the surrounding environment (Marczak et al., 2017). The recognition of EPS by specific LysM receptors modulates plant-bacteria recognition and potentially competition for nodulation (Geddes et al., 2014; Kawaharada et al., 2015). The two basic nodule morphologies appear to exhibit different rhizobial exopolysaccharide requirements. In rhizobia inducing determinate nodules, EPS mutants still induce effective nodules, with EPS playing a signaling role at the late stages of both infection thread initiation and bacterial release (Kelly et al., 2013). However, in symbioses forming indeterminate nodules, EPS is absolutely essential for a successful interaction (reviewed by Fraysse et al., 2003; Acosta-Jurado et al., 2021). EPS-altered mutants (exhibiting conserved LPS) generated in an isogenic strain, $R$. loti PN184, able to nodulate Lotus pedunculatus (determinate nodules) and Leucaena leucocephala (indeterminate nodules) showed that they were fully effective on a determinatenodulating host but ineffective on the indeterminate one (Hotter and Scott, 1991). Working on L. japonicus, Kawarada and coworkers showed that perception of EPS synthesized by M. loti is important for maintaining an intracellular infection mode, with the plant LysM receptor protein EPR3 acting in the root cortex and nodule primordia to support and sustain the containment of rhizobia and to facilitate an efficient infection process. They observed a reduced and delayed nodulation either in the plant epr3 mutants or in $M$. loti mutants affected in EPS biosynthesis due to a reduction of the normal intracellular infection thread mode and increased intercellular infection (Kawaharada et al., 2017). Interestingly, ITs of determinate nodules are narrower than those from indeterminate ones, where EPS is a critical component of the internal matrix and relevant for the cortex rhizobial invasion (Stacey et al., 1991). In indeterminate nodules, bacteria have to spread out by means of continuous IT penetration in the new cortex cells, whereas in the determinate nodules they spread by division of already infected cells (Fraysse et al., 2003). Consequently, EPS plays an important role in determining symbiotic competence; indeed, $R$. leguminosarum bv. trifolii strains overexpressing the biosynthesis gene pssA overproduced EPS and showed enhanced competitiveness, nodule occupancy, and symbiotic effectiveness with Trifolium pratense (red clover) in relation to their wild type strains (Janczarek et al., 2009). Likewise, S. meliloti 1021 mutant overexpressing the exoY gene, which encodes the enzyme responsible for the first step in succinoglycan (EPSI) biosynthesis, resulted in an increased production of this surface polymer and, as a consequence, enhanced symbiotic effectiveness with Medicago truncatula plants (Jones, 2012). Succinoglycan is essential for infection thread formation on plant hosts and has been shown to be more important than Nod factors for bacterial survival inside nodules (Maillet et al., 2020). Among other surface polysaccharides, EPS also seems to play an essential role also in protection against host plant defense during early and late symbiotic stages of rhizobial growth, when rhizobia are subjected to a prolonged oxidative burst from their plant hosts (Santos et al., 2001; D'Haeze and Holsters, 2004; Davies and Walker, 2007). Succinoglycan also protects $S$. meliloti against the antimicrobial activity of plant-derived nodule-specific cysteinerich peptides in nodule occupancy and bacteroid differentiation and potentially against $\mathrm{pH}$ stress inside symbiosomes (Montiel et al., 2017; Arnold et al., 2018). Regarding LPS, contrary to what happens with EPS, an intact polymer seems to be needed for the formation of narrow ITs from determinate nodules (Stacey et al., 1991). A B. japonicum mutant defective in LPS synthesis was able to attach and induce root hair curling but failed to penetrate the root and induce ITs and nodules in soybean. However, in indeterminate nodules, mutants with alterations in this surface polymer formed ITs, although they led to an altered symbiotic phenotype in Ensifer meliloti during the association with alfalfa that affects the timing of nodule emergence, the infection development, and the strain competitiveness for nodulation (Lagares et al., 1992; Campbell et al., 2002; Sharypova et al., 2003). Ips $B$ is a nice example of a surface mutation which does not affect the rate of infection initiation (i.e., no change in root nodule distribution) but the rate of nodule development and emergence. Such post-infection delay strongly reduces nodulation competitiveness by a factor of nearly 100 . Beside this, the $l p s B$ mutation shows how surface changes may also modify the host range for N2-fixation (Niehaus et al., 1998).

A common characteristic found in rhizobiales and other soil bacteria is the large number of ATP-binding cassette (ABC) transporters and methyl-accepting chemiotaxis proteins $(\mathrm{M})$, which allows them to thrive in such a heterogenous and changing environment as soil, and to detect a high number of metabolites and influence their motility (Mauchline et al., 2006). ABC transporters, such as the genes teuBAC1C2, required for the utilization of root exudates (Rosenblueth et al., 1998) may confer competitive ability (Oger et al., 1997). The genes encoding the amino acid transporter AapJQMP have been shown to be up-regulated in bean and pea bacteroids, indicating the importance of the plant supply for branched-chain amino acids isoleucine and valine (Green et al., 2019). The assimilation of different nutrients and energy also influences competitiveness at different stages, such as during multiplication and survival in bulk soil (Sessitsch et al., 2002) or multiplication from the nodule environment after root senescence thanks to the ability 
of catabolizing rhizopines, a compound made by bacteroids and subsequently catabolized by free-living cells of the producing strain (Murphy et al., 1987; Gordon et al., 1996). Recent work on genetically engineered M. truncatula and alfalfa plants that produce and exude rhizopine into the rhizosphere opened the door for the regulation of the root microbiome (Geddes et al., 2019b). Plant-supplied carbon can be diverted into storage molecules, such as polyhydroxybutyrate (PHB), increasing future survival and reproduction during free-living life-history stages once released into the soil after nodule senescence (Aneja et al., 2005; Ratcliff et al., 2008). Indeed, model prediction shows that the amount of PHB stored per cell could support the survival of active cells for a few days, or over a century for sufficiently dormant cells (Muller and Denison, 2018). Their PHB quantification experiments with Bradyrhizobium field isolates done in starvation conditions suggest that $\mathrm{PHB}$ is partitioned asymmetrically in dividing cells and that high-PHB isolates used more $\mathrm{PHB}$ over the first month, still retaining sufficient $\mathrm{PHB}$ for potential long-term survival in a dormant state. Homoserine is another amino acid shown to confer an advantage on those R. leguminosarum bv. viciae strains whose Sym plasmid harbors the genetic determinants for the catabolism of this plantassociated compound in the rhizosphere of pea roots (Hynes and O'Connell, 1990). The catabolism of other compounds such as rhamnose, proline, myo-inositol, and glycerol has also been reported to influence competitiveness (Jimenez-Zurdo et al., 1995; Oresnik et al., 1998; Fry et al., 2001; Kohler et al., 2010; Ding et al., 2012). Transcriptional regulators involved in metabolism are also important. A Bradyrhizobium diazoefficiens mutant with an impaired $r$ sh gene (from $\underline{r}$ elA-spoT homologous), responsible for a pleiotropic adaptation under stressful and starving conditions known as the stringent response, was less competitive than the wild type in occupying soybean nodules (Pérez-Giménez et al., 2021). A functional rosR is also important for competitive nodulation. This regulator has pleiotropic effects leading to defective attachment, infection thread formation, and bacteroid differentiation and senescence (Bittinger et al., 1997; Janczarek et al., 2010; Rachwał et al., 2016). As pssA, in terms of competitiveness, an increase in the quantity of nodules formed by strains carrying multiple copies of ros $R$ was observed in comparison to $R$. leguminosarum bv. trifolii wild type strains (Janczarek et al., 2009).

\section{Genetic Components to Prevent the Growth of Other Bacterial Cells}

In terms of interference competition, one strategy is the production of antibacterial compounds, such as bacteriocins, which may play a role in competition for rhizosphere and root colonization (Hirsch et al., 1980; Oresnik et al., 1999; Venter et al., 2001). The quorum sensing system cinRIS is responsible for the production of the small bacteriocin, produced by strains of all three biovars of $R$. leguminosarum and inhibiting the growth of several strains of this species (Schripsema et al., 1996). The antibiotic trifolitoxin also improves rhizosphere colonization and increases competitiveness for nodule occupancy of clover (Schwinghamer and Belkengren, 1968; Triplett and Barta, 1987;
Robleto et al., 1998). Members of the nodule microbiome of Medicago sativa also produce britacidins and tyrocidines (Hansen et al., 2020), supporting the idea that, in addition to nitrogen fixation, legume root nodules are sites of active antimicrobial production, presumably to provide protection from pathogens that might infect these organs and ensure that nitrogen-fixation activity is preserved. The presence of secretion systems in PGPRs and rhizobial strains may play a role in their plant growth-promoting (PGP) functions and also provides means of interference competition against other strains in the rhizosphere (Gupta et al., 2014). For instance, the T1SSd proteins orthologous to the PrsD and PrsE proteins are required for biofilm formation (Russo et al., 2006). The T3SS, T4SS, and T6SS are generally used to inject effector proteins, such as nodulation outer proteins (Nops), directly into eukaryotic host cells or into other bacteria, which can mediate compatibility with the host in rhizobia, modulating partner choice (Jimenez-Zurdo et al., 1995; Marie et al., 2003; Ausmees et al., 2004; Nelson and Sadowsky, 2015). The secretion of Nops through T3SS in the presence of flavonoids is able to induce the transcription of nodulation genes (JiménezGuerrero et al., 2017) and might modulate the plant defense response upon infection (Pérez-Giménez et al., 2021). While T3SS orthologs are present in $R$. etli CFN42, S. fredii HH103, B. japonicum USDA110, and Rhizobium sp. NGR234, they are not common in $R$. leguminosarum or Sinorhizobium species (Black et al., 2012). The T4SS, encoded by traGDCAFBHMR, is involved in conjugal transfer, whereas the T4SS-pili (virB1virB11) system is involved in the colonization of surfaces in gram-negative bacteria (Juhas et al., 2008). S. meliloti with a truncated T4SS was less competitive for nodule formation compared to wild type (Nelson et al., 2017). T6SS, encoded by the imp (tss) and hcp clusters, was first identified in the $\alpha$-rhizobial strain R. leguminosarum (Bladergroen et al., 2003) and shown to be important for nodulation of pea plants. Impaired T6SS mutants in $R$. etli Mim1 have been shown to generate small, white nodules in Phaseolus vulgaris, although with similar activity (Salinero-Lanzarote et al., 2019). The authors suggested a positive role for T6SS in competition with other soil bacteria, as it was active at a high cell density and in the presence of plant exudates. Many gram-negative bacteria use this secretion system for killing competitors (Schwarz et al., 2010; de Campos et al., 2017; Allsopp et al., 2020) and presumably even as an inter-bacterial communication system mediated by the T6SSquorum sensing cross-talk (Gallique et al., 2017). These transport secretion systems are often found in the accessory genome of rhizobial strains.

\section{Genetic Components for Establishing an Efficient Symbiosis}

Rhizobial genomes are extremely variable (MacLean et al., 2007), with the secondary replicons generally more genetically diverse between strains than is the primary chromosome (Galardini et al., 2013). Chromids - large replicons carrying essential genes and adopting plasmid-type maintenance and a rep $A B C$ replication system - appear to contain genus-specific genes in Rhizobium, Ensifer, and Agrobacterium (Harrison et al., 2010). 
When an organism arrives in a new niche, it needs to adapt to the new environment, undergoing genome expansions due to the duplication of existing genes or the acquisition of new ones through horizontal gene transfer in order to acquire new functions that improve the fitness of these strains in the new environment (Martins Dos Santos et al., 2004; Aguilar et al., 2018). This is the case, for example, with nodD. NodD regulates the expression of the nodABCFE cluster and is therefore involved in Nod factor production. Nod factor decorations are critical for host specificity and their levels are tightly regulated during infection (Krönauer and Radutoiu, 2021). Five nodD reiterations were found in $R$. tropici CIAT899, necessary to engage the symbiont in nodulation with different legume plants (del Cerro et al., 2015). They were also present in different nitrogen-fixing rhizobial strains from $P$. vulgaris, suggesting a potential role in host range (Peralta et al., 2016). In R. leguminosarum bv. trifolii, a second copy, NodD2, enhanced nodule colonization and competitiveness in symbiosis with clover (Ferguson et al., 2020). These accessory nod genes may reflect the variations within the interactions among rhizobial and plant species. Indeed, nodD has been extensively used for the identification and classification of rhizobial isolates (Boivin et al., 2020; Fields et al., 2021). Sequence heterogeneity within symbiotic plasmids also shows extensive genomic rearrangements, recombination rates, lateral transfer events, and relaxation or intensification of selective pressures (González et al., 2003). Indeed, the diversity of associations between genomic backgrounds and Sym genotypes may be greater in bulk soils than in nodules, as the first symbiotic organs are formed by the most competitive strains' genotypes for a given host plant (Louvrier et al., 1996; Laguerre et al., 2003) triggering autoregulation of nodulation which start to inhibit further nodulation (Mortier et al., 2012). Legume hosts seem to select differentially within the same soil populations. As an example, pea and faba bean have been reported to select A1 and $\mathrm{B} 1$ nod groups of $R$. leguminosarum bv. viciae as their symbiotic partner to form nodules (Laguerre et al., 2003; Mutch and Young, 2004; Jorrin and Imperial, 2015). When R. etli nodC variants from the centers of bean genetic diversification were inoculated on wild and cultivated P. vulgaris (common bean), yield was best when plant and bacteria were from the same geographic origin, suggesting mutual symbiotic selectivity and coevolution (Aguilar et al., 2004). During the growth cycle of beans, more competitive rhizobia will return to the soil after nodule senescence and therefore contribute to an increase in their representation in soil, explaining this synergism (Aguilar et al., 2004). The minimal symbiotic genome has been defined recently in E. meliloti, allowing gain-of-function approaches that can be used to elucidate genes in the Sym plasmid, as well as those genes from other highly competitive rhizobia that contribute to nodulation competitiveness (Geddes et al., 2021).

\section{Genetic Components to Promote Plant Growth}

The term biofertilizer comprises formulations of different living microbial cells, either a single strain or multiple strains, that promote plant growth by increasing nutrient availability and acquisition (Riaz et al., 2020). Thus, elite rhizobial inoculants, besides the traits involved in competition, should also combine a subset of other important traits, with PGP abilities among them (Vessey, 2003; Lugtenberg and Kamilova, 2009; Jaiswal et al., 2021). These traits enhance yields and cause positive changes in soil structure and microbial community. The production of phytohormones is a major property that has evolved in plantassociated bacteria. It leads to an increased size of plant root system and, subsequently, the exploitation of a larger soil volume, thus improving the mineral and aqueous nutrition available to the plant (Cai et al., 2018). In most bacterial pathways, auxin biosynthesis mainly relies on tryptophan, which acts as a biosynthetic precursor of indole acetic acid (IAA), a common auxin produced by rhizobacteria, and as a signal inducing $i p d C / p p d C$ transcription. E. meliloti $\operatorname{tr} p E$ mutants, blocked at the first step in tryptophan biosynthesis, form $\mathrm{N}_{2}$-ineffective symbionts (Barsomian et al., 1992). Similarly, Tn5-induced B. japonicum tryptophan synthetase mutants lacked the ability to fix nitrogen and were symbiotically defective (Kummer and David Kuykendall, 1989). This deficiency in $\mathrm{N}_{2}$-fixation seems to be most likely due to the pleitropic effects of the amino acid auxotrophy, with the host plant unable to supply the nutrients needed for the endosymbiont to establish an effective symbiosis. Interestingly, the tryptophan auxotroph mutant $\operatorname{tr} p B$ of $R$. etli CE3 was unable to produce Nod factors in free-living conditions unless tryptophan was added to the growth medium, rendering nodules ineffective in its symbiotic partner $P$. vulgaris. This indicated that even though this $\operatorname{trp} B$ mutant was able to induce the development of a nodule primordium, a shortage of aromatic amino acids during nodule invasion strongly altered its ability to subsequently invade the nodule and differentiate into bacteroids (Taté et al., 1999). Some PGPR of the genera Bacillus, Enterobacter, or Pseudomonas promote plant growth by solubilizing phosphate from the soil. Genes implicated in phosphate solubilization are the sensor kinase $p h o R$, and the genes involved in regulation and transport, phoUB and pstSCAB (Chhabra et al., 2013). Intriguingly, bean nodule bacteroids seem to be phosphate-limited (Green et al., 2019). The secretion of siderophores also promotes plant growth by enhancing iron uptake and utilization (Liu et al., 2017). These molecules have a high affinity for $\mathrm{Fe}^{3+}$, scavenging iron from environmental stocks where soil iron is low and reducing it to $\mathrm{Fe}^{2+}$ for uptake and utilization (Kramer et al., 2020). As an example, Rhizobactin 1021 is a hydroxymate siderophore produced by the soil bacterium E. meliloti 2011 which appears to contribute to the competitive ability of free-living E. meliloti in iron-depleted soils (Persmark et al., 1993; Barton et al., 1996; Lynch et al., 2001).

\section{Future Understanding of Rhizobial Genomes}

Understanding the mechanisms behind competitiveness for nodulation may lead to improved inoculation strategies (Bourion et al., 2018). A plethora of molecular mechanisms play a role in competition, concerning both microbe-microbe, and plantmicrobe interactions. Sequencing efforts have improved our understanding of rhizobial genomes, with sequence analysis of 
whole genomes enabling in-depth studies and comparisons of genome structures (Burghardt et al., 2018; Epstein et al., 2018; Cavassim et al., 2020). The high-throughput identification of genes relevant to competitiveness was first approached with signature-tagged mutagenesis (STM) in planta, which allowed screening of hundreds of mutants in one passage through the host (Pobigaylo et al., 2008). This study identified 38 mutations in genes that were not previously known to be involved in competitiveness or symbiosis in E. meliloti, confirming 23 with attenuated competitiveness phenotypes when they were tested for competition against the wild type. Among them are some of the genetic determinants already mentioned, such as: $\operatorname{trpC}$ and $\operatorname{trpF}$, involved in the conversion of tryptophan to IAA; $p s t A$ and $p s t C$, encoding components of the high-affinity phosphate transporter system PstSCAB; or iolA, encoding a methylmalonate-semialdehyde dehydrogenase involved in myoinositol catabolism (Pobigaylo et al., 2008). STM also allowed the identification of more than a hundred genes in E. meliloti associated with rhizosphere colonization of a host (alfalfa) and a non-host plant (pea; Salas et al., 2017), supporting the ancient character of those genes. The high-throughput identification of essential genes in specific conditions is today performed by transposon-insertion sequencing (Tn-Seq or INSeq), a saturation insertion mutagenesis performed in a pool of colonies in a given environment. Each colony contains a single insertion that can be mapped across an entire genome by next-generation sequencing, allowing the determination of gene fitness at genome-scale (Goodman et al., 2011; Perry and Yost, 2014; Chao et al., 2016). This method has been applied in rhizobia, leading to the elucidation of genes involved in competition, such as the ORF SMc00911, conserved and highly expressed in the nodule. This insertion mutant strain strongly outcompeted the E. meliloti 1021 wild type strain (Queiroux et al., 2012). More recently, this method has allowed the identification at a genome-wide scale of genes involved in various stages of the rhizobial lifestyle, including those genes required when in competition with other bacteria, which were traditionally missed in the artificial environment of inoculation with a single strain (Wheatley et al., 2020). Among the mutants assesed in this study for their ability to compete against wildtype to form nodules were the genes encoding the chemotaxis protein CheA, glutamine synthetase II $(g \ln I I)$, or the polysaccharide biosynthesis protein PssD. A more powerful method moving this field forward are unique but random DNA barcodes used in insertional mutagenesis (BarSeq). The abundance of transposon insertions can be followed with a single PCR step to amplify the barcodes followed by NGS, allowing the study of gene fitness across multiple growth conditions (Robinson et al., 2014; Wetmore et al., 2015). Multi-strain barcoding can be used for analyzing how bacteria interact with the plant and one another during competitive root colonization competition coupled to sequencing (Cole et al., 2017; Knights et al., 2021).

Active competition between rhizobial strains might take place throughout the entire course of the symbiosis, from the recruitment of the endosymbionts in the rhizosphere to nodule decay (Wielbo et al., 2010). These methods will improve our understanding of which phases in the nodulation process are exposed to competition. Indeed, although much less explored relative to competition in the rhizosphere, we have previously seen that competition also takes place inside plant nodules, highlighting the complexity of the interactions between the plant host and rhizobia. Studies on rhizobial competitiveness have revealed that competition between strains also extends to the process of infection thread initiation and the growth of rhizobia in the infection threads (Stuurman et al., 2000; Duodu et al., 2009). The INSeq work carried out in R. leguminosarum bv. viciae has shown that the chemotaxis cluster Che2 is needed in the infection thread (Wheatley et al., 2020). Numerous molecular techniques are available for the evaluation of competitive abilities of rhizobia in the rhizosphere, whereas the formation of infection threads remains poorly understood. New methods based on Periodic Acid-Schiff to visualize the three-dimensional structure of infection threads in sufficient detail using novel and traditional cell wall fluorescent labels combined with laser confocal scanning microscopy presents an exciting opportunity for research in this area, including competition (Rae et al., 2021).

\section{METHODS TO ASSESS RHIZOBIAL COMPETITIVENESS FOR NODULATION}

Experiments involving single- and multi-inoculation with pea plants have shown that the nodulation ability of a strain does not predict its competitiveness for nodulation and is not correlated with its $\mathrm{N}_{2}$-effectiveness (Bourion et al., 2018). The high competitiveness of a given strain does not ensure high nitrogen-fixing efficiency or high biomass production for the plant, indicating that competitiveness for nodulation is controlled by multiple genetic factors from both the host and the rhizobia strain. This study highlighted that competitiveness for nodulation and nitrogen fixation efficiency must both be considered as selection criteria for improving pea crop production. Although many unknows remain regarding the molecular and genetic mechanisms driving competition for nodulation, it has become clear that, in the development of elite rhizobial inoculants, it is necessary to consider colonization and competition for nodulation separately from symbiotic nitrogen fixation abilities (Checcucci et al., 2017). Therefore, one of the main challenges is still the selection of elite rhizobial strains based on their high performance in the field due to their symbiotic performance, combined with relevant genetic features (Checcucci et al., 2017; Aguilar et al., 2018).

Despite one of the first co-inoculation assays being presented in 1930 by Löhnis (1930), follow by Dunham and Baldwin (1931), there has been limited progress in this area due to the complexity of directly observing and identifying interactions between bacteria and plants. The methods to assess competitiveness have traditionally been time-consuming and restricted to a small sample size. However, several techniques are now emerging, based on advances in imaging (Jeckel and Drescher, 2020) and sequencing technologies, which allow a high-throughput approach, as summarized in Table 2.

Competition assays were initially performed using morphological, serological, or antibiotic markers that allowed 
TABLE 2 | The most frequently used methods to assess rhizobial competitiveness for nodulation.

\begin{tabular}{|c|c|c|c|c|}
\hline Method & Principle & Pros & Cons & $\begin{array}{l}\text { Example of latest studies } \\
\text { using this method to assess } \\
\text { competitiveness }\end{array}$ \\
\hline $\begin{array}{l}\text { Antibiotic markers } \\
\text { Graham, 1969; } \\
\text { Josey et al., } 1979\end{array}$ & $\begin{array}{l}\text { Scoring rhizobial } \\
\text { infection by plating } \\
\text { nodule samples on } \\
\text { suitable selected } \\
\text { media }\end{array}$ & $\begin{array}{l}\text { - No need for sophisticated equipment; } \\
\text { - No need to genetically modify the } \\
\text { strains; } \\
\text { - Competitiveness of strain not affected. }\end{array}$ & $\begin{array}{l}\text { - Limited number of strains can be } \\
\text { evaluated; } \\
\text { - Mixed nodules are often missed; } \\
\text { - Relies on strain viability and culturability } \\
\text { in different antibiotics which becomes } \\
\text { very labor intensive. }\end{array}$ & $\begin{array}{l}\text { Bogino et al., 2011; Laguerre } \\
\text { et al., 2012; Bourion et al., } \\
2018\end{array}$ \\
\hline $\begin{array}{l}\text { Strain-specific } \\
\text { fingerprints } \\
\text { De Bruijn, 1992; } \\
\text { Laguerre et al., } 2003\end{array}$ & $\begin{array}{l}\text { Targeting specific } \\
\text { plasmid profiles or } \\
\text { genes; afterwards } \\
\text { patterns of the } \\
\text { resulting PCR } \\
\text { products are analyzed }\end{array}$ & $\begin{array}{l}\text { - Suitable as a first step to classify closely } \\
\text { related strains in large collections. }\end{array}$ & $\begin{array}{l}\text { - Requires strict standardization of } \\
\text { reaction parameters; } \\
\text { - Complex comparative analysis of } \\
\text { banding patterns; } \\
\text { - Does not allow the identification of } \\
\text { mixed nodules. }\end{array}$ & $\begin{array}{l}\text { Lardi et al., 2017; Irisarri et al., } \\
\text { 2019; Pastor-Bueis et al., } 2019\end{array}$ \\
\hline $\begin{array}{l}\text { Sequential double } \\
\text { staining to detect gusA } \\
\text { and celB } \\
\text { Sessitsch et al., } 1996\end{array}$ & $\begin{array}{l}\text { Scoring of nodule } \\
\text { infection by color } \\
\text { detection after } \\
\text { enzymatic reactions }\end{array}$ & $\begin{array}{l}\text { - Allows efficient scoring of single or } \\
\text { double nodule infections without } \\
\text { requiring sophisticated equipment; } \\
\text { - Stable insertion of marker genes, ideal } \\
\text { for ecological experiments; } \\
\text { - Can be used in large-scale assays and } \\
\text { in the presence of an unmarked } \\
\text { background population. }\end{array}$ & $\begin{array}{l}\text { - Only possible to score two tagged } \\
\text { strains simultaneously; } \\
\text { - Toxic buffers are needed for the } \\
\text { enzymatic reaction to distinguish } \\
\text { nodule occupancy; } \\
\text { - Not possible to recover viable rhizobia } \\
\text { from stained nodules. }\end{array}$ & $\begin{array}{l}\text { Sánchez-Cañizares and } \\
\text { Palacios, 2013; Ferguson et al., } \\
\text { 2020; Mendoza-Suárez et al., } \\
2020 \\
\text { Westhoek et al., } 2021\end{array}$ \\
\hline $\begin{array}{l}\text { Fluorescent proteins } \\
\text { Stuurman et al., } 2000\end{array}$ & $\begin{array}{l}\text { Detection of dual } \\
\text { fluorescence by } \\
\text { microscopy }\end{array}$ & $\begin{array}{l}\text { - High resolution even at single cell level; } \\
\text { - Viable rhizobia can be recovered from } \\
\text { nodules. }\end{array}$ & $\begin{array}{l}\text { - Only a few nodules per plant or a small } \\
\text { plant sample size can be assessed due } \\
\text { to microscopy complexity. }\end{array}$ & $\begin{array}{l}\text { Checcucci et al., 2016; Regus } \\
\text { et al., 2017; Bellabarba et al., } \\
2020\end{array}$ \\
\hline $\begin{array}{l}\text { NGS of full genome, } \\
\text { core genes or } \\
\text { accessory genes }\end{array}$ & $\begin{array}{l}\text { Analysis of partial or } \\
\text { full genome to identify } \\
\text { individual strains }\end{array}$ & $\begin{array}{l}\text { - Large numbers of rhizobial strains can } \\
\text { be assessed simultaneously; } \\
\text { - Measures relative strain diversity; } \\
\text { - Tracks dynamic changes in strain } \\
\text { populations. }\end{array}$ & $\begin{array}{l}\text { - DNA samples are pooled, loosing } \\
\text { information of individual strain-nodule } \\
\text { relation; } \\
\text { - Pre-sequencing of the genomes from } \\
\text { the strains is needed; } \\
\text { - Complex sequencing data analysis. }\end{array}$ & $\begin{array}{l}\text { Ji et al., 2017; Burghardt et al., } \\
\text { 2018; Boivin et al., 2020; } \\
\text { Moeskjær et al., } 2020\end{array}$ \\
\hline $\begin{array}{l}\text { NGS of synthetic DNA } \\
\text { fragments } \\
\text { Mendoza-Suárez et al., } \\
2020\end{array}$ & $\begin{array}{l}\text { Introduced unique } \\
\text { barcodes (IDs) are } \\
\text { detected by NGS to } \\
\text { score bacterial } \\
\text { populations in } \\
\text { individual nodules }\end{array}$ & $\begin{array}{l}\text { - Large numbers of rhizobial strains can } \\
\text { be assessed simultaneously; } \\
\text { - Strains not previously isolated and } \\
\text { genome-sequenced can be identified; } \\
\text { - Information at a nodule level; } \\
\text { - Easy identification of mixed nodules; } \\
\text { - Simultaneous assessment of } \\
\text { competitiveness and effectiveness. }\end{array}$ & $\begin{array}{l}\text { - High-throughput cloning methods are } \\
\text { needed and bacteria library preparation; } \\
\text { - A blue-light transilluminator is needed } \\
\text { to detect GFP nodules from tagged } \\
\text { strains vs native strains. }\end{array}$ & Mendoza-Suárez et al., 2020 \\
\hline
\end{tabular}

for strain discrimination (Löhnis, 1930; Holland, 1966; Graham, 1969; Josey et al., 1979), followed by strain-specific genomic fingerprints (De Bruijn, 1992; Laguerre et al., 2003; Figure 2A). These methods are labor-intensive, as they involve isolating strains from nodules and plating them in selective media or complex and sometimes barely-reproducible PCR profile analyses. Marker genes such as lacZ (Drahos et al., 1986) and $\operatorname{lu} x A B$ (O'Kane et al., 1988) facilitated observation of the bacteria-plant interaction, although the downsides were that B-galactosidase activity from lac $Z$ had a high background in both rhizobia and the plant host, and the luciferase assays with lux $A B$ needed sophisticated equipment to be detected.

A tool that simplified these assays was the use of marker genes and chemical staining to detect gusA (Streit et al., 1992), and the simultaneous detection of gusA and celB (Sessitsch et al., 1996) by enzymatic activities rendering colored products (Figure 2B), or by fluorescent proteins (Stuurman et al., 2000; Figures 2C,D). However, these assays are still restricted to inoculum mixes of only two strains. More novel approaches today allow high-throughput assays by using either NGS of full genomes, core genes, or accessory genes, or NGS of synthetic DNA fragments (Mendoza-Suárez et al., 2020). It is worth noting the promoter driving the expression of the reporter genes. While constitutive promoters have been standard, Wilson et al. (1995b) and Sessitsch et al. (1996) used promoters that express only in symbiosis and nitrogen-fixing conditions and are a more specific alternative, such as the nifH promoter. A broader, more novel approach is the use of a universal nifH synthetic promoter, based on a consensus sequence adapted to different rhizobia by Mendoza-Suárez et al. (2020). These reporters can be either replicated in stable low-copy plasmids (Pini et al., 2017; Geddes et al., 2019a), through a quick conjugation step with the strains of interest, or can be integrated in the genome by stable miniTn7 vectors (Romero-Jiménez et al., 2015). The transformational breakthrough in Mendoza-Suárez et al. (2020) is the ability to simultaneously assess competitiveness and estimate rates of nitrogen fixation in individual nodules of pea plants. This is achieved thanks to the combination of a module for evaluating 


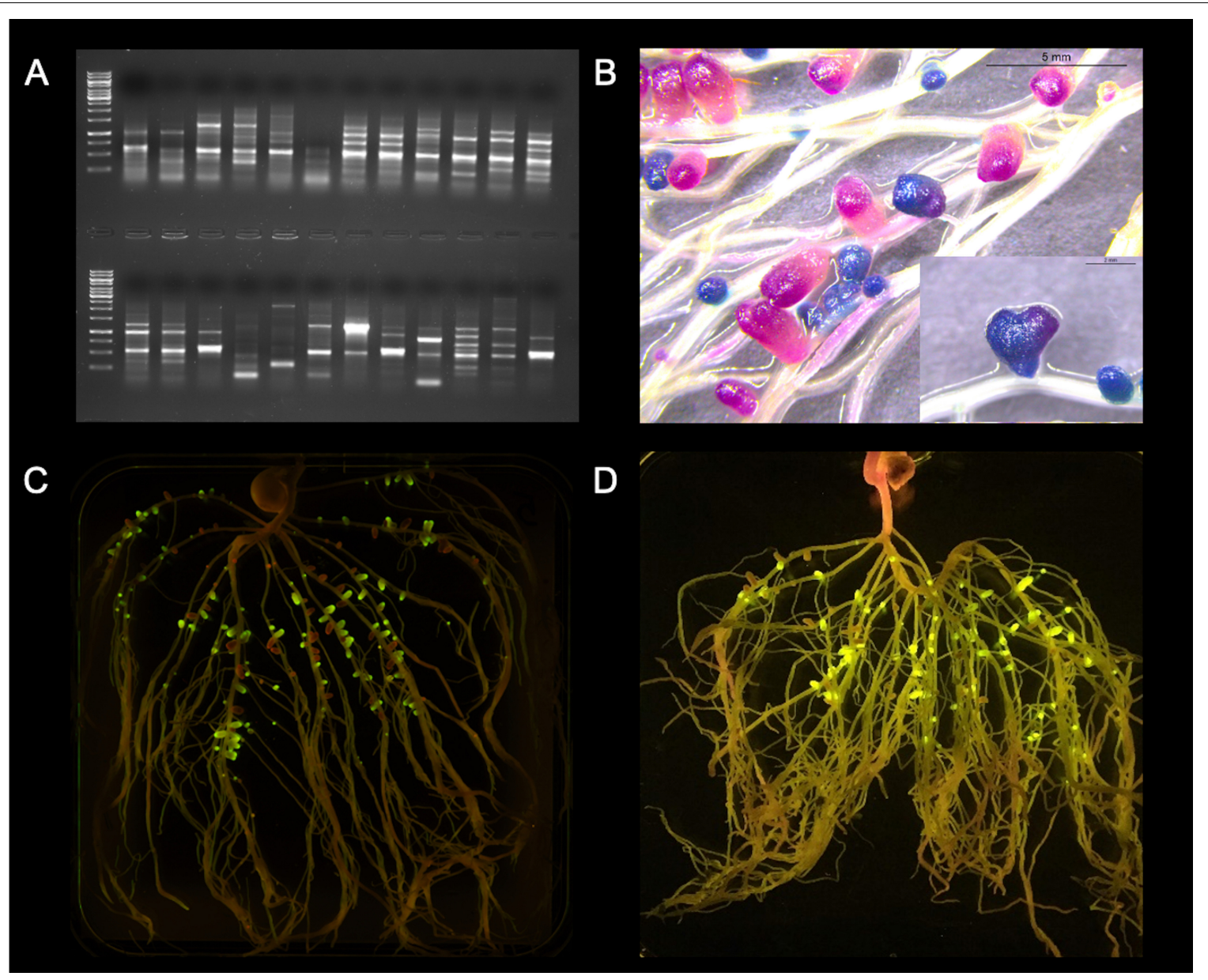

FIGURE 2 | Visualization of some methods for assessing rhizobial competitiveness for nodulation. (A) Strain-specific genomic fingerprints: ERIC-PCR from same plant nodule isolates from a trapping assay using faba bean as a host; (B) Sequential double staining to detect gus $A$ and celB: Pea roots were sequentially double-stained with Magenta-GlCA and X-Gal after thermal treatment, resulting in pink nodules formed by UPM791gusA (gusA constitutively expressed) and blue nodules formed by Rlv3841celB (celB constitutively expressed); (C) Fluorescent proteins: Rlv3841 labeled with mini-Tn7 J23104 GFP or mCherry, respectively; and (D) NGS of synthetic DNA fragments: Example of pea roots grown in non-sterile soil and exposed to a blue-light transilluminator. Tagged rhizobia, expressing GFP under PsnifH control, lead to fluorescent nodules, while indigenous rhizobia do not. Photo credit: (A,B,D) Marcela Mendoza-Suárez; (C) Laura Clark.

$\mathrm{N}_{2}$-effectiveness that included a consensus nifH (nitrogenase) promoter driving nodule-specific expression of green fluorescent protein as reporter gene, together with a second module consisting of a unique synthetic nucleotide sequence as a barcode strain identifier (ID; Figure 2D), allowing the screening of large libraries of bacterial strains.

We must not forget that competitiveness of a Rhizobium strain and how efficiently it fixes nitrogen is determined by its genetics and physiology, in interaction with the legume host genotype (Laguerre et al., 2003; Burghardt et al., 2018; Boivin et al., 2020) and the inoculation context, determined by soil influence (Batista et al., 2015) and climatic conditions (Frey and Blum, 1994; Vuong et al., 2017). The population of rhizobia in different soils is heterogeneous and varies quantitatively and qualitatively, responding to different abiotic and biotic factors (Graham, 2008; Kasper et al., 2019). A given elite strain may thrive in one climate or soil type but fail in a different environment to which it is poorly adapted. Therefore, when elite strains are found, these are for a particular soil and plant genotype, and may well not perform as well in a different plant genotype or different environment (Figure 3). It is of utmost importance that future competition assays are performed in non-sterile conditions; ultimately, rhizobial strains are not alone in the rhizosphere. It is therefore essential to apply and improve existing techniques, such as those of Burghardt et al. (2018) and Mendoza-Suárez et al. (2020), to other Rhizobium species. Like this, more studies could combine the assessment of a large number of strains for nodule occupancy using different host genotypes with the assessment of symbiotic $\mathrm{N}_{2}$-fixation in agricultural soils, whilst minimizing financial and time costs through increased testing efficiency.

\section{HOW MANY STRAINS ARE THERE IN A MIXED NODULE?}

Nodules containing more than one rhizobial strain, called "mixed nodules," were identified several decades ago (Johnston and Beringer, 1976). Experimental results have shown 


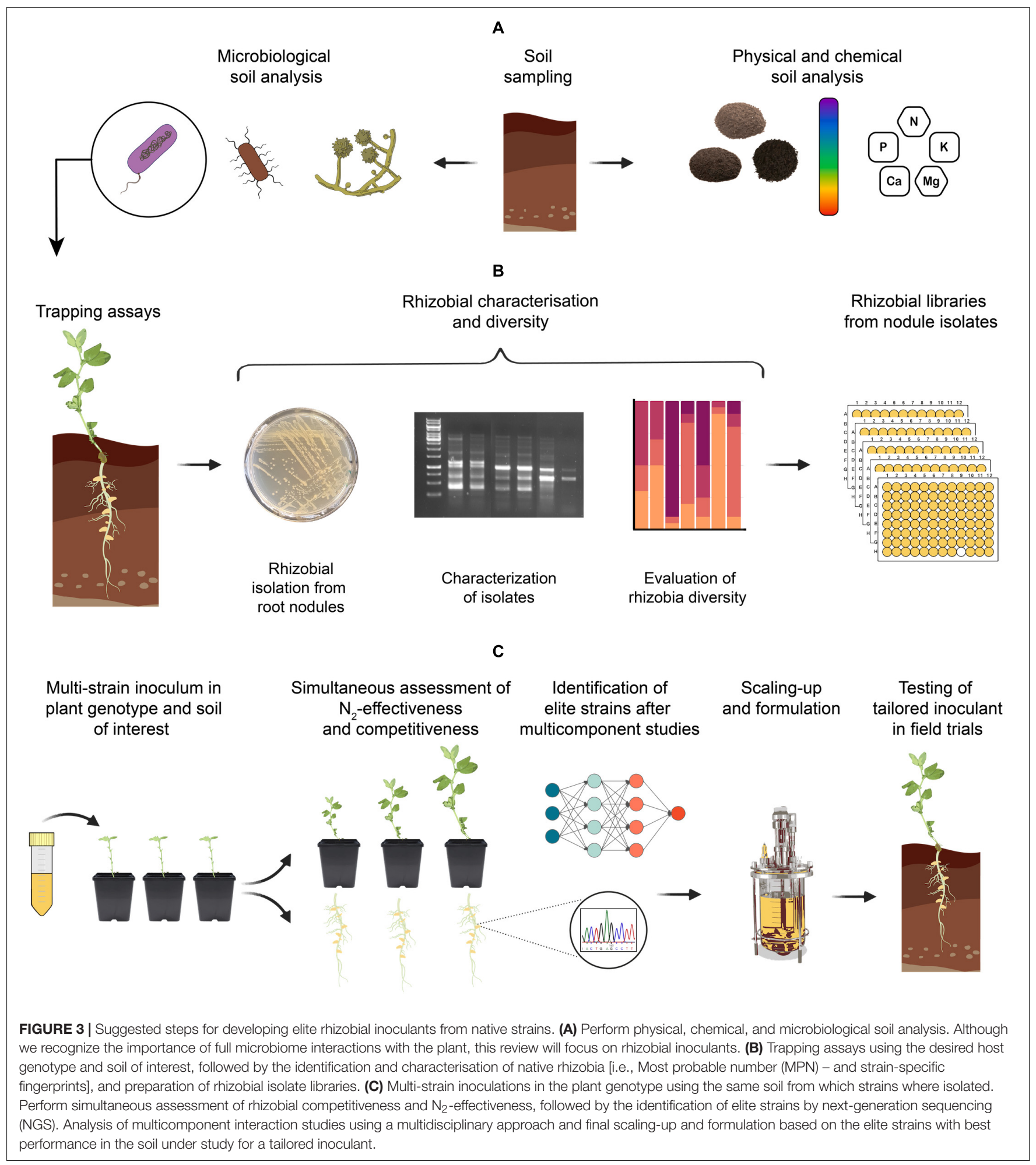

that the percentage of mixed nodules is sufficiently high that it should be carefully considered in rhizobial studies, particularly in competition assays (May and Bohlool, 1983; Moawad and Schmidt, 1987). However, these competition experiments were traditionally conducted with two-strain mixtures. Thanks to the development of new methods to assess rhizobial competitiveness, advances in microscopy, and the continued decrease in price of NGS, it has now been possible to assess more simultaneouslycompeting strains, which has also made the easy identification of mixed nodules possible. These new studies suggest that not 
only are mixed nodules more common than thought previously, but they can also be occupied by more than two different strains. In fact, Mendoza-Suárez et al. (2020) found up to six different strains in a single nodule using unique barcode identifiers (ID). This also reinforces the hypothesis that there may be cooperative partnerships between strains.

\section{CHEATERS AND PLANT SANCTIONING BEHAVIORS}

Since multiple rhizobial strains may occupy the same nodule (Checcucci et al., 2016; Mendoza-Suárez et al., 2020), cheating behaviors have emerged (Sachs et al., 2010; Checcucci et al., 2016; Regus et al., 2017). Experiments with near-isogenic mutants demonstrated that a $\mathrm{N}_{2}$-ineffective mutant had a similar level of competitiveness to its parent (Amarger, 1981; Daubech et al., 2017), supporting the idea that plants do not select rhizobial strains by their fixing abilities at root entry level. Indeed, $\mathrm{N}_{2}$-ineffective rhizobial strains with superior competitiveness often gain advantage over $\mathrm{N}_{2}$-effective strains, despite offering suboptimal growth to their plant host (Sachs et al., 2010). Perennial legumes, where nodulation is a continuous and sequential process, establish symbiosis with less competitive rhizobial strains when they have no other choice. A study performed in Caragana microphylla with different Mesorhizobium strains demonstrated how the plant host could be infected with a more favorable rhizobial strain when the nodules were first occupied by less competitive rhizobial strains (Ji et al., 2017). However, if a legume had nodules occupied by its most favorable rhizobial strain first, it was unlikely that other rhizobial strains in the rhizosphere would be able to form new nodules on the roots, even if the density of the other strains was higher. This dynamism over time and life phase of the host plant has been reported in the nodule microbiome of $M$. sativa, indicating that its members strongly interact through cooperation and competition (Hansen et al., 2020). In fact, pea plants have been shown to tolerate intermediate fixers only when a better strain was not available (Westhoek et al., 2021). Postinfection plant control over bacteroid metabolism is essential due to the high fitness cost of nodule formation and bacteroid maintenance. The plant host must therefore monitor symbiotic performance and respond accordingly (Ledermann et al., 2021). However, plants cannot select effective nitrogen-fixing rhizobia from a mixture of effective and ineffective strains in the soil in the early stages of the symbiotic interaction (Westhoek et al., 2021). Instead, to avoid cheaters displacing effective symbionts once the infection has occurred, legumes limit cheating through host sanctions, which reduce the fitness of cheaters, and partner choice, where each partner can identify and reject forming relationships with cheaters (West et al., 2002; Kiers et al., 2003; Kiers and Denison, 2008; Sachs et al., 2010; Oono et al., 2011; Daubech et al., 2017; Westhoek et al., 2021). Sanctioning of ineffective nodules occurs by reducing the number of viable cells present in nodules and reducing their reproductive success (Kiers et al., 2003), by preferentially promoting nodule development in number and size with most BNF-efficient rhizobia due to the stimulation of plant cell multiplication and bacteroid differentiation (Laguerre et al., 2012), or presumably by reducing resource allocation to a nodule and shutting it down (Kiers et al., 2003; Westhoek et al., 2021). As seen in mixed nodules, where nodules are co-occupied by different strains, the host plant appears to spatially structure symbionts, separating in individual plant cells effective from ineffective partners. Therefore, when nodules are co-inhabited with a fixing strain, the inefficient strain is sanctioned rapidly in a cell-autonomous way (Regus et al., 2017). This means that plant sanctions are targeted specifically to those individual host cells housing ineffective partners, being an effective host strategy to sanction poorly performing strains. Even in mixed nodule infections, each individual plant cell appears to only have one strain. Plant nodules have been described as autonomous compartments where the host is able to actively rewire investment away from symbiont reproduction, and toward nitrogen fixation (Chomicki et al., 2020). In evolutionary terms, compartmentalization of host-microbe interactions helps to stabilize cooperation by allowing hosts to: (i) isolate symbionts and control their reproduction; (ii) reward cooperative symbionts and punish or stop interactions with non-cooperative symbionts; and (iii) reduce direct conflict among different symbiont strains in a single host (Chomicki et al., 2020). Hosts with symbiotic promiscuity (analyzed in detail in Perret et al., 2000) could face a stronger selection pressure to evolve effective postinfection discrimination, although the mechanisms by which the host monitors individual nodules, once formed, are still largely unknown (Chomicki et al., 2020).

\section{CURRENT PRODUCTION OF INOCULANTS}

The use of inoculants is well stablished in agricultural systems. Based on Bradyrhizobium strains, soybean is currently the crop that consumes the most inoculant production worldwide (Santos et al., 2019). Rhizobial strains have traditionally been isolated either from bulk soil (Figure 3A) in a semi-selective medium or with trapping assays designed for a soil and a host of interest (Figure 3B; Laguerre et al., 2003). For a rhizobial strain to be considered as a potential inoculant, the easiest approach is to first characterize the isolate in the laboratory and show its effectiveness at nitrogen fixation, its ability to successfully fight for rhizosphere colonization, and its relative competitiveness against native rhizobia for nodule occupancy. Screening for the relative ability of rhizobia to compete for the rhizosphere appears a quite good predictor of nodule occupancy as indicated by the strikingly linear impact that access to the rhizosphere has been shown to have on nodule occupancy (Salas et al., 2017). Once these characteristics have been determined, it is crucial to test rhizobial strains in greenhouse and field trials to analyze the effects of the inoculant treatment on agronomic traits, such as: nodulation, plant biomass, shoot $\mathrm{N}$ content, grain yield, and/or grain N content (Werner and Newton, 2005; Lupwayi et al., 2006). Once the screen for a set of elite rhizobia performing well in the rhizosphere has been made, these wild type strains can then be incorporated into more complex assays, 
such as Tn-Seq/INSeq or BarSeq, where the mutagenesis can be done in soil conditions where a natural microbiome will be present, or genome comparisons between an elite strain versus non-competitive strains to identify the genetic determinants involved in competition.

Those strains selected as inoculants are typically grown at a fermenter scale and used to coat seeds of compatible legume hosts to introduce them into the soil (Figure 3C; diCenzo et al., 2019). However, this inoculation method often results in a high density of bacteria near the seed, with nodulation restricted to the upper tap root but reduced in the more distal part of the tap root and the lateral roots due to the low density of the inoculant strain in the bulk soil (Vlassak and Vanderleyden, 1997). Alternatively, infurrow inoculation - placing the rhizobial strain in the seed bed is an approach that enhances rhizobial motility and consequently, increases nodule occupancy (López-García et al., 2009). It also works well for legumes infected by crack entry, such as peanut and bradyrhizobia, as the chances of encountering breaks in the secondary root epidermis and establishing symbiosis are increased (Bogino et al., 2011). Therefore, to maximize rhizobial inoculant efficacy, research must focus on the following key aspects: the intrinsic characteristics of the rhizobial strain; the delivery system into the soil, known as inoculant formulation; the optimization of the production process by industrial fermentation, and the compatibility with the farmer's practices (Catroux et al., 2001; Temprano et al., 2002; Herridge et al., 2008; Checcucci et al., 2017; Pastor-Bueis et al., 2019).

Although an elite strain is an essential prerequisite in the development of successful inoculants, there are several factors to consider when working in laboratory conditions. Firstly, nodule-dominant strain genotypes from soil populations do not necessarily show superior competitiveness for nodulation compared to minor occupants when evaluated under non-soil conditions (Laguerre et al., 2003). Secondly, legumes grown in sterile conditions under nitrogen starvation regimes can show significant growth differences between the inoculated and noninoculated treatments. However, real agricultural conditions are never entirely devoid of nitrogen, and populations of native rhizobia are usually present (Wilson et al., 1995a). As the sole inoculant applied to legumes under laboratory or controlled conditions, specific strains of rhizobia may increase nitrogen fixation (Wielbo et al., 2010); however, once these strains are applied to legumes under real agricultural conditions, they often fail in the competition with native strains for nodulation due to soil conditions, rooting depth, humidity, temperature, and the inoculant formulation (López-García et al., 2002; Naeem et al., 2004; Yates et al., 2011; Drew et al., 2012). Finally, another important trait in an inoculant is the survival rate; both in the carrier - a wide range of carriers can be used (peat, compost, vermiculite, perlite, and sand) - and in the soil. The strain used as the inoculant needs to be either robust or well protected in order to survive under harsh conditions (Parnell et al., 2016). Rhizobia should survive and grow in the soil in the absence of the host plant and be able to colonize the host plant rhizosphere prior to competition for root infection and nodule formation (Laguerre et al., 2003). The use of coated seeds is the most convenient delivery system, but while rhizobia survive well in inoculant formulations, some die rapidly after seed-coating owing to osmotic and desiccation stress (O’Callaghan, 2016; Atieno et al., 2018). Formulation of inoculants is a crucial issue, but little research has been conducted on this subject. It can improve field performance, shelf life, and stability while reducing variability (Parnell et al., 2016; Santos et al., 2019). Both liquid and solid formulations are widely used. Currently, the most widespread dry formulation consists of peat as a carrier, plus other additives such as bacterial protectors and adhesives (Bashan et al., 2014; Atieno et al., 2018; Santos et al., 2019). Drying of microorganisms has been recognized as an efficient way of long-term preserving; however, desiccation is a physiologically challenging process, so protectants are added externally to the bacterial cells prior to drying (Berninger et al., 2017). Among other mineral or organic carriers, compost and biochar-the solid, carbon-rich product of heating biomass with the exclusion of air, with high porosity, large specific surface area, adsorption ability, and high cation exchange capacity-have been proposed as carriers with outstanding properties (Albareda et al., 2008; Arif et al., 2017; Egamberdieva et al., 2017; Song et al., 2020). It has also been shown that the combination of an inoculant strain together with a carbon source, such as glycerol in microgranules, confers a competitive advantage to the inoculant bacterium (Duquenne et al., 1999; Sessitsch et al., 2002). Biomaterials adopted from the field of drug delivery have been proposed as a technological opportunity for developing an advanced seedcoating (Zvinavashe et al., 2019). These authors have developed a seed-coating based on silk fibronin and trehalose that stabilizes and preserves rhizobia in saline and, possibly, arid environments. However, the non-biological components of the formulations remain key bottlenecks in the commercial development of inoculants (Bashan et al., 2014; Pastor-Bueis et al., 2019). For all these reasons, experiments in soil conditions are crucial, with the ultimate goal being the design of a successful inoculant based on an elite native strain with an adequate formulation which can result in greater grain yields than without the use of rhizobial inoculants. Or, in some cases, grain yields can even be similar or higher compared to chemical fertilization practices in inoculated fields with native strains (Mulas et al., 2015). Of course, the latest results have to be considered in an arid soil context, where the loss of total nitrogen input is leached at rates of up to 58\% ( $\mathrm{Hu}$ et al., 2010). In seeking elite strains for several pulse legumes in areas of difficult soils placing substantial stress on inoculant survival, Howieson et al., 2000, successfully developed an inoculant program based on crossrow experiments in successive years. The authors screened for nitrogen fixation, edaphic adaptation and performance in situ of rhizobial strains originally collected from the Mediterranean region, which reflects the edaphic characteristics of the target soils in Southern Australia. Inoculation with these better adapted strains, selected for their superior $\mathrm{N}_{2}$-effectiveness, increased yield and nodulation in legume crops in infertile soils combining acidity and desiccation. Moreover, despite the competition for nodulation by background rhizobia at the site, assessment of nodule occupancy by the inoculant strains revealed all were present in $>90 \%$ of nodules, securing the establishment of 
pulse crops in difficult soils. Below we explain why rhizobial inoculant strains that are applied to legumes in field conditions often fail to nodulate legumes in competition with native strains (López-García et al., 2002; Naeem et al., 2004; Yates et al., 2011; Drew et al., 2012).

\section{GENETIC STABILITY OF INOCULANT STRAINS}

The genetic instability of inoculant strains and the exchange of symbiotic plasmids contribute to the diversity of naturalized populations and the lack of inoculant persistence (Ronson and Lowther, 1995). Several reports based on the phylogeny of nod genes-located in the symbiotic plasmid or symbiotic islandshave shown that the Sym plasmid is not strictly associated with the chromosomal background in natural populations of rhizobia (Schofield et al., 1987; Young and Wexler, 1988; Laguerre et al., 1992; Louvrier et al., 1996; Andrews et al., 2018). Since lateral gene and plasmid transfers are the major drivers of symbiotic phenotype evolution, bacterial genospecies are not ecologically relevant for symbiotic traits (Kumar et al., 2015; Andrews et al., 2018; Boivin et al., 2020). Symbiovars reflect the symbiosis plasmid rather than chromosome diversity (Kumar et al., 2015).

While the transfer of symbiosis genes to bacteria adapted to local soil conditions can allow them to become symbionts of previously incompatible legumes growing in those soils (Sullivan et al., 1995; Barcellos et al., 2007; Rivas et al., 2007; Andrews et al., 2018), in the case of inoculant strains this common and widespread phenomenon in fact results in the opposite outcome. Natural transfer of symbiotic islands by mobile integrative and conjugative elements has been demonstrated in field trials with mesorhizobia (Sullivan et al., 1995; Sullivan and Ronson, 1998; Nandasena et al., 2006, 2007; Hill et al., 2021), where resident non-nodulating bacteria accepted symbiotic genes from the inoculant Mesorhizobium strain, often resulting in highly competitive strains with poor nitrogen fixation capabilities that outcompete the original inoculant, potentially rendering it ineffective (Sullivan et al., 1995; Nandasena et al., 2007; Sotelo et al., 2011). Self-transmissible plasmids may be maintained within field isolates because they confer selective advantages on host strains (Meade et al., 1985). Genes required for the catabolism of plant exudates or the utilization of a range of carbon sources are often located on plasmids. For example, the genes involved in the degradation of rhamnose were reported to be induced by root extracts from the host plant, playing a role in competition of R. leguminosarum bv. trifolii in the early stages of the symbiotic interaction (Oresnik et al., 1998). Mutants unable to utilize this carbon source had impaired competitive abilities. The same applies to homoserine, an amino acid abundantly exuded by pea roots. $R$. leguminosarum bv. viciae strains able to use homoserine as a carbon and nitrogen source were found to be prevalent in pea nodules (Hynes and O'Connell, 1990; Vanderlinde et al., 2014). However, this does not exclude the possibility that some genes present on the chromosome may also contribute to the symbiotic phenotype and its variation (Boivin et al., 2020; Ferguson et al., 2020).

\section{ERRATIC PERFORMANCE OF INOCULANTS}

In many locations, native rhizobial populations are either not effective, or do not occur in sufficient number to meet the nitrogen demand of promiscuous cultivars, leading to a safer inoculation approach with exotic elite rhizobial strains instead of relying on resident strains of unknown potential (Chibeba et al., 2017). Moreover, although rhizobia are ubiquitous in the soil, the introduction of new plant species in a different location usually results in a lack of co-evolved rhizobial strains in soils abroad (Mpepereki et al., 2000; Giller, 2001; Simonsen et al., 2017; Bouznif et al., 2019). Successful introduction of crops into new regions is, therefore, dependent on inoculation with exotic rhizobia. Many examples in the Southern hemisphere illustrate this phenomenon, such as African soils and soybean cultivars (Okogun and Sanginga, 2003; Abaidoo et al., 2007; Klogo et al., 2015), forage and grain legumes in Australian and New Zealand soils (Ronson and Lowther, 1995; Hill et al., 2021), soybean in Argentina (Iturralde et al., 2019), common bean in Brazilian soils (Hungria et al., 2003), or forage production of Lotus corniculatus and clover in Uruguay (Sotelo et al., 2011, Irisarri et al., 2019). However, this leads to another problem with promiscuous cultivars: commercial inoculants based on exotic rhizobial strains selected for their efficiency in nitrogen fixation fail to establish a successful symbiosis by not being competitive against inefficient native rhizobia (Martínez-Romero, 2003; Pastor-Bueis et al., 2019; Shamseldin and Velázquez, 2020). Indeed, the absence of the inoculated strain in the nodules leads to low productivity, attributed to poor performance of the inoculant, and lack of consistency in field performance (Sotelo et al., 2011; Irisarri et al., 2019). The infection of legume crops by native populations of ineffective but competitive local rhizobia is known as "the competition problem" and causes yield decreases of legume crops (Triplett and Sadowsky, 1992; Friesen, 2012). Due to these inoculation problems, farmers prefer to use chemical fertilizers rather than rely on the capacity of the inoculants to carry out an efficient BNF (Pastor-Bueis et al., 2019). Therefore, the design of tailored inoculants by selecting naturallyevolved and locally-sourced rhizobia with outstanding symbiotic performance (effectiveness) that are already adapted to the agroclimatic conditions of a particular region (competitiveness) is of fundamental importance for agricultural lands worldwide in order to tackle this competition problem and increase crop yields without the use of nitrogen fertilizers (Chibeba et al., 2017; Pastor-Bueis et al., 2019). Indeed, local adaptation is a more important evolutionary force shaping microbial cooperation than is partner choice (Batstone et al., 2020). External factors are major determinants of the high competitiveness of soil native populations, such as the physiological condition and the growth age of the rhizobial culture, the distribution of the bacterial cells into the soil, the presence of salt and the soil $\mathrm{pH}$ of the sampling location, the soil surface coverage and soil temperatures during the crop season, or the resistance to the herbicides applied to the soil as part of the agricultural practice (López-García et al., 2002; Albareda et al., 2006; Iturralde et al., 2019). Therefore, different field scenarios need to be investigated. Methods to conduct field 
trials with those elite strains are being developed to ascertain their superiority in fixing nitrogen in the presence of native and/or commercial strains (Mendoza-Suárez et al., 2020).

\section{MOVING TOWARD TAILORED INOCULANTS}

The addition of chemical fertilizers has a negative impact on the soil microbiome, as plants no longer need to interact with beneficial bacteria to access the nutrients that are being externally supplied and, therefore, the diversity of the microbial community in the root environment is reduced (Zhu et al., 2016; Kavamura et al., 2018). A study performed in wheat has shown that chemical fertilizers reduce the number of bacteria associated with the roots that solubilise nutrients such as nitrogen, potassium, phosphorous, iron, and zinc (Reid et al., 2021). Strikingly, the number of growth-promoting bacteria living on the roots fell from $91 \%$ of total bacteria for unfertilized plants, to just $19 \%$ for those that received the fertilizer dose. Chemical nitrogen inputs for a period of 22 years have guided the evolution of less-mutualistic rhizobia which produce $17-30 \%$ less biomass on Trifolium species compared to plants inoculated with rhizobia from non-fertilized control plots (Weese et al., 2015), which clearly shows the great negative environmental consequences of long-term input of chemical fertilizers in agricultural systems. Therefore, optimizing microbiome function is essential for sustainable agriculture (Hartmann et al., 2015).

On the other hand, Batstone et al. (2020) have found that after five plant generations, $M$. truncatula select for a more efficient E. meliloti symbiont. The superior host benefits were observed when the plant-microbe partnership shared an evolutionary history. Incorporating rhizobial strains with closely-related hosts is more likely to be effective, but it is necessary to give the new microbe sufficient time to adapt to their new environment. Schlaeppi and Bulgarelli (2015) were the first authors to foresee next-generation agriculture that aims to customize practices and tools, such as microbial inoculants, inspired by the concept of personalized diagnosis in medicine. Bell et al. (2019) proposed a customizable field-scale microbial inoculant that could have long-lasting effects with appropriate implementation. These innovative biofertilizer technologies based on tailored design and the implementation of effective agricultural microbiome manipulations and management strategies will benefit both consumers and producers of worldwide food supply (Busby et al., 2017; Mitter et al., 2021). Particularly in marginal soils of arid and semi-arid regions, inoculation is a crucial agricultural practice, with BNF being the major way to introduce nitrogen (Zahran, 1999). Not only that, but rhizobial inoculants also have other important and promising ecological applications, such as the restoration of habitats or the conservation of endangered plant species (Rodríguez-Echeverría et al., 2003; Thrall et al., 2005; Beyhaut et al., 2014; Navarro et al., 2014).

Although, as we have seen, it is well known that taking into account Rhizobium genotype (Gr) interactions together with root and soil microbiota ecology (M), plant host genotype (Gp), and/or environment (E), is important for evaluating whether selected strains are going to be suitable as inoculants (Figure 3C; Roskothen, 1989; Hungria and Vargas, 2000; Sessitsch et al., 2002; Busby et al., 2017; diCenzo et al., 2019) — note that authors have used different abbreviations-much research on competition has nevertheless focussed on changing only one or a few variables at a time. This is due to the complexity of distinguishing specific strains of interest, the limitations of running scaled-up plant experiments, and a lack of knowledge in understanding the ecological component of heterogenous communities and complex environments (including field trials). Of course, the big challenge is which one of these variables is most important to study or control? Although multicomponent interaction studies can be perceived as an overwhelming and titanic task, we can rely on a multidisciplinary approach to tackle the problem. Indeed, more and more multicomponent interaction studies are being conducted (Vuong et al., 2017; Burghardt et al., 2018; Gunnabo et al., 2019; Batstone et al., 2020; Mendoza-Suárez et al., 2020; Fagorzi et al., 2021), and they are already generating important knowledge to help understand some of these interactions and give more weight to the performance of rhizobial inoculants. Additionally, the rapid progress in NGS with open-source laboratory equipment automation (Figure 3C; Wong et al., 2018; Faiña et al., 2020), and the application of machine learning in big data analysis of microbiome studies (Cammarota et al., 2020; Ghannam and Techtmann, 2021) and in biological-image analysis (Berg et al., 2019; Chung et al., 2020; Tausen et al., 2020), will make multicomponent interactions studies more achievable, providing the opportunity to identify a larger number of elite strains in less time. The introduction of a wider number of variables in the experimental assays conducted to identify elite strains will increase the probability of designing rhizobial inoculants with better performance under field conditions. Once elite strains are identified in greenhouse experiments exploring multicomponent interactions, strict testing needs to be conducted in field trials before their commercialisation (Soumare et al., 2020; Figure 3C). Due to the complexity and genetic diversity within the soil and plant microbiome, it is unlikely that one formulation will be effective for all fields (Mitter et al., 2021). Yet, it might be unrealistic to design tailored inoculants for each individual field (Parnell et al., 2016). However, it may be possible to first carry out broader and cheaper assays to assess soil factors such as $\mathrm{pH}$, nutrient and organic material content, and then correlate the physicochemical properties of the field with an already established collection of strains that perform well in those field conditions. Tailored inoculants may also become cheaper with increased production, which gives an opportunity to learn how to improve the production process and begin a positive-feedback cycle of increasing demand and falling prices (Schmidt et al., 2017; Lafond et al., 2020). For this reason, we suggest that efforts should be made to develop a multidisciplinary validation system that targets optimal performance for a given set of components. Thanks to progress in multicomponent interactions and multidisciplinary studies, it could become possible to offer farmers tailored rhizobial inoculants in the near future by conducting full physicochemical and microbiological soil analysis, in a similar way to fertilizer consultants offering 
an "inoculant recommendation" for specific legume crops to grow in the next agricultural cycle (Figure 3 ). This inoculant advice would work in the same way that chemical fertilizer recommendations based on soil testing are currently offered and would reinforce and complement the farmer's current agricultural practice.

\section{CONCLUSION}

Ensuring the sustainability of agriculture becomes more important in light of future challenges such as climate change or the rapid growth of the human population (Schlaeppi and Bulgarelli, 2015). Next-generation agriculture will greatly benefit from the development of rhizobial bioinoculants based on elite strains that combine effectiveness and competitiveness under field conditions. The aforementioned areas of research in competition are shedding light on many of the processes that affect the performance of the inoculant and should be taken into account. The advances in imaging and sequencing technologies are improving our knowledge about all the stages in the symbiotic process, deciphering the mechanisms of cheating and cooperative bacterial behaviors, uncovering the genetic features behind competition and allowing high-throughput approaches to assess this trait, also under field conditions. Moreover, machine learning will allow us to automate assays and data analysis. In the longer term, these advances will contribute to solving the competition problem by allowing cost-efficient design and production of site-specific inoculants.

\section{REFERENCES}

Abaidoo, R. C., Keyser, H. H., Singleton, P. W., Dashiell, K. E., and Sanginga, N. (2007). Population size, distribution, and symbiotic characteristics of indigenous Bradyrhizobium spp. that nodulate TGx soybean genotypes in Africa. Appl. Soil Ecol. 35, 57-67. doi: 10.1016/j.apsoil.2006.05.006

Acosta-Jurado, S., Fuentes-romero, F., Ruiz-sainz, J. E., Janczarek, M., and Vinardell, J. M. (2021). Rhizobial exopolysaccharides: genetic regulation of their synthesis and relevance in symbiosis with legumes. Int. J. Mol. Sci. 22, 1-27. doi: 10.3390/ijms22126233

Aguilar, A., Mora, Y., Dávalos, A., Girard, L., Mora, J., and Peralta, H. (2018). Analysis of genome sequence and symbiotic ability of rhizobial strains isolated from seeds of common bean (Phaseolus vulgaris). BMC Genomics 19:645. doi: 10.1186/s12864-018-5023-0

Aguilar, O. M., Riva, O., and Peltzer, E. (2004). Analysis of Rhizobium etli and of its symbiosis with wild Phaseolus vulgaris supports coevolution in centers of host diversification. Proc. Natl. Acad. Sci. U.S.A. 101, 13548-13553. doi: 10.1073/PNAS.0405321101

Albareda, M., Dardanelli, M. S., Sousa, C., Megías, M., Temprano, F., and Rodríguez-Navarro, D. N. (2006). Factors affecting the attachment of rhizospheric bacteria to bean and soybean roots. FEMS Microbiol. Lett. 259, 67-73. doi: 10.1111/j.1574-6968.2006.00244.x

Albareda, M., Rodríguez-Navarro, D. N., Camacho, M., and Temprano, F. J. (2008). Alternatives to peat as a carrier for rhizobia inoculants: solid and liquid formulations. Soil Biol. Biochem. 40, 2771-2779. doi: 10.1016/j.soilbio.2008. 07.021

Allsopp, L. P., Bernal, P., Nolan, L. M., and Filloux, A. (2020). Causalities of war: the connection between type VI secretion system and microbiota. Cell. Microbiol. 22:e13153. doi: 10.1111/cmi.13153

Amarger, N. (1981). Competition for nodule formation between effective and ineffective strains of Rhizobium meliloti. Soil Biol. Biochem. 13, 475-480. doi: 10.1016/0038-0717(81)90037-7

\section{AUTHOR CONTRIBUTIONS}

MM-S and CS-C wrote the manuscript. SA and PP provided critical feedback. All authors conceived and approved the final version of the manuscript.

\section{FUNDING}

This work was supported by The Leverhulme Trust (grant RPG-2019-246), the Biotechnology and Biological Sciences Research Council (grant number BB/N003608/1), and the ERA-NET Cofound SusCrop (grant $\mathrm{N}^{\circ} 771134$ ), being part of the Joint Programming Initiative on Agriculture, Food Security and Climate Change (FACCEJPI; SA).

\section{ACKNOWLEDGMENTS}

This article is dedicated to Tomas Ruíz-Argüeso, who was a warm, inspiring, and incredibly supportive mentor of many researchers working in the field of nitrogen fixation. We thank Leila Walker for editing the manuscript and Laura Clark for providing the competition assay photo using fluorescent proteins. We apologize to any researchers whose work was omitted without intention.

Ampe, F., Kiss, E., Sabourdy, F., and Batut, J. (2003). Transcriptome analysis of Sinorhizobium meliloti during symbiosis. Genome Biol. 4:R15. doi: 10.1186/gb2003-4-2-r15

Andrews, M., De Meyer, S., James, E. K., Stępkowski, T., Hodge, S., Simon, M. F., et al. (2018). Horizontal transfer of symbiosis genes within and between rhizobial genera: occurrence and importance. Genes 9:321. doi: 10.3390/ genes 9070321

Aneja, P., Zachertowska, A., and Charles, T. C. (2005). Comparison of the symbiotic and competition phenotypes of Sinorhizobium meliloti PHB synthesis and degradation pathway mutants. Can. J. Microbiol. 51, 599-604. doi: 10.1139/ w05-042

Anyango, B., Wilson, K. J., Beynon, J. L., and Giller, K. E. (1995). Diversity of rhizobia nodulating Phaseolus vulgaris L. in two Kenyan soils with contrasting pHs. Appl. Environ. Microbiol. 61, 4016-4021. doi: 10.1128/aem.61.11.40164021.1995

Arif, M. S., Shahzad, S. M., Riaz, M., Yasmeen, T., Shahzad, T., Akhtar, M. J., et al. (2017). Nitrogen-enriched compost application combined with plant growth-promoting rhizobacteria (PGPR) improves seed quality and nutrient use efficiency of sunflower. J. Plant Nutr. Soil Sci. 180, 464-473. doi: 10.1002/ jpln.201600615

Arnold, M. F. F., Penterman, J., Shabab, M., Chen, E. J., and Walker, G. C. (2018). Important late-stage symbiotic role of the Sinorhizobium meliloti Exopolysaccharide Succinoglycan. J. Bacteriol. 200:e00665-17. doi: 10.1128/JB. 00665- 17

Atieno, M., Wilson, N., Casteriano, A., Crossett, B., Lesueur, D., and Deaker, R. (2018). Aqueous peat extract exposes rhizobia to sub-lethal stress which may prime cells for improved desiccation tolerance. Appl. Microbiol. Biotechnol. 102, 7521-7539. doi: 10.1007/s00253-018-9086-2

Ausmees, N., Jacobsson, K., and Lindberg, M. (2001). A unipolarly located, cellsurface-associated agglutinin, RapA, belongs to a family of Rhizobium-adhering proteins (Rap) in Rhizobium leguminosarum bv. trifolii. Microbiology 147, 549-559. 
Ausmees, N., Kobayashi, H., Deakin, W. J., Marie, C., Krishnan, H. B., Broughton, W. J., et al. (2004). Characterization of NopP, a type III secreted effector of Rhizobium sp. strain NGR234. J. Bacteriol. 186, 4774-4780. doi: 10.1128/JB.186. 14.4774-4780.2004

Badri, D. V., and Vivanco, J. M. (2009). Regulation and function of root exudates. Plant. Cell Environ. 32, 666-681. doi: 10.1111/j.1365-3040.2009.01926.x

Bais, H. P., Weir, T. L., Perry, L. G., Gilroy, S., and Vivanco, J. M. (2006). The role of root exudates in rhizosphere interactions with plants and other organisms. Annu. Rev. Plant Biol. 57, 233-266. doi: 10.1146/annurev.arplant.57.032905. 105159

Barcellos, F. G., Menna, P., Batista, J. S. D. S., and Hungria, M. (2007). Evidence of horizontal transfer of symbiotic genes from a Bradyrhizobium japonicum inoculant strain to indigenous diazotrophs Sinorhizobium (Ensifer) fredii and Bradyrhizobium elkanii in a Brazilian savannah soil. Appl. Environ. Microbiol. 73, 2635-2643. doi: 10.1128/AEM.01823-06

Barnett, M. J., Toman, C. J., Fisher, R. F., and Long, S. R. (2004). A dual-genome Symbiosis Chip for coordinate study of signal exchange and development in a prokaryote-host interaction. Proc. Natl. Acad. Sci. U.S.A. 101, 16636-16641. doi: 10.1073/pnas.0407269101

Barsomian, G. D., Urzainqui, A., Lohman, K., and Walker, G. C. (1992). Rhizobium meliloti mutants unable to synthesize anthranilate display a novel symbiotic phenotype. J. Bacteriol. 174, 4416-4426. doi: 10.1128/jb.174.13.4416-4426.1992

Barton, L. L., Johnson, G. V., Schitoskey, K., and Wertz, M. (1996). Siderophoremediated iron metabolism in growth and nitrogen fixation by alfalfa nodulated with Rhizobium meliloti. J. Plant Nutr. 19, 1201-1210. doi: 10.1080/ 01904169609365191

Bashan, Y., De-Bashan, L. E., Prabhu, S. R., and Hernandez, J. P. (2014). Advances in plant growth-promoting bacterial inoculant technology: formulations and practical perspectives (1998-2013). Plant Soil 378, 1-33. doi: 10.1007/s11104013-1956-x

Batista, L., Irisarri, P., Rebuffo, M., Cuitiño, M. J., Sanjuán, J., and Monza, J. (2015). Nodulation competitiveness as a requisite for improved rhizobial inoculants of Trifolium pratense. Biol. Fertil. Soils 51, 11-20. doi: 10.1007/s00374-014-0946-3

Batstone, R. T., O’Brien, A. M., Harrison, T. L., and Frederickson, M. E. (2020) Experimental evolution makes microbes more cooperative with their local host genotype. Science 370, 23-26. doi: 10.1126/science.abb7222

Bauer, W. D., and Caetano-Anollés, G. (1990). Chemotaxis, induced gene expression and competitiveness in the rhizosphere. Plant Soil 129, 45-52. doi: 10.1007/BF00011690

Bell, T. H., Kaminsky, L. M., Gugino, B. K., Carlson, J. E., Malik, R. J., Hockett, K. L., et al. (2019). Factoring ecological, societal, and economic considerations into inoculant development. Trends Biotechnol. 37, 572-573. doi: 10.1016/j.tibtech. 2019.02.009

Bellabarba, A., Bacci, G., Decorosi, F., Aun, E., Azzarello, E., Remm, M., et al. (2020). Competitiveness prediction for nodule colonization in Sinorhizobium meliloti through combined in vitro tagged strain characterization and genomewide association analysis. bioRxiv [Preprint]. doi: 10.1101/2020.09.15.298034

Berg, S., Kutra, D., Kroeger, T., Straehle, C. N., Kausler, B. X., Haubold, C., et al. (2019). ilastik: interactive machine learning for (bio)image analysis. Nat. Methods 16, 1226-1232. doi: 10.1038/s41592-019-0582-9

Berninger, T., González López, Ó, Bejarano, A., Preininger, C., and Sessitsch, A. (2017). Maintenance and assessment of cell viability in formulation of nonsporulating bacterial inoculants. Microb. Biotechnol. 11, 277-301. doi: 10.1111/ 1751-7915.12880

Beyhaut, E., Larson, D. L., Allan, D. L., and Graham, P. H. (2014). Legumes in prairie restoration: evidence for wide cross-nodulation and improved inoculant delivery. Plant Soil 377, 245-258. doi: 10.1007/s11104-013-1999-z

Bittinger, M. A., Milner, J. L., Saville, B. J., and Handelsman, J. (1997). rosR, A determinant of nodulation competitiveness in Rhizobium etli. Mol. Plant Microbe Interact. 10, 180-186. doi: 10.1094/MPMI.1997.10.2.180

Black, M., Moolhuijzen, P., Chapman, B., Barrero, R., Howieson, J., Hungria, M., et al. (2012). The genetics of symbiotic nitrogen fixation: comparative genomics of 14 rhizobia strains by resolution of protein clusters. Genes 3, 138-166. doi: 10.3390/genes3010138

Bladergroen, M. R., Badelt, K., and Spaink, H. P. (2003). Infection-blocking genes of a symbiotic Rhizobium leguminosarum strain that are involved in temperature-dependent protein secretion. Mol. Plant Microbe Interact. 16, 53-64. doi: 10.1094/MPMI.2003.16.1.53
Bogino, P., Nievas, F., Banchio, E., and Giordano, W. (2011). Increased competitiveness and efficiency of biological nitrogen fixation in peanut via infurrow inoculation of rhizobia. Eur. J. Soil Biol. 47, 188-193. doi: 10.1016/j. ejsobi.2011.01.005

Boivin, S., Ait Lahmidi, N., Sherlock, D., Bonhomme, M., Dijon, D., Heulin-Gotty, K., et al. (2020). Host-specific competitiveness to form nodules in Rhizobium leguminosarum symbiovar viciae. New Phytol. 226, 555-568. doi: 10.1111/nph. 16392

Bourion, V., Heulin-Gotty, K., Aubert, V., Tisseyre, P., Chabert-Martinello, M., Pervent, M., et al. (2018). Co-inoculation of a Pea core-collection with diverse Rhizobial strains shows competitiveness for nodulation and efficiency of nitrogen fixation are distinct traits in the interaction. Front. Plant Sci. 8:2249. doi: $10.3389 /$ fpls.2017.02249

Bouznif, B., Guefrachi, I., Rodríguez de la Vega, R. C., Hungria, M., Mars, M., Alunni, B., et al. (2019). Phylogeography of the Bradyrhizobium spp. Associated With Peanut, Arachis hypogaea: Fellow Travelers or New Associations?. Front. Microbiol. 10:2041. doi: 10.3389/fmicb.2019.02041

Brockwell, J., Bottomley, P. J., and Thies, J. E. (1995). Manipulation of rhizobia microflora for improving legume productivity and soil fertility: a critical assessment. Plant Soil 174, 143-180. doi: 10.1007/BF00032245

Burghardt, L. T., Epstein, B., Guhlin, J., Nelson, M. S., Taylor, M. R., Young, N. D., et al. (2018). Select and resequence reveals relative fitness of bacteria in symbiotic and free-living environments. Proc. Natl. Acad. Sci. U.S.A. 115, 2425-2430. doi: 10.1073/PNAS.1714246115

Busby, P. E., Soman, C., Wagner, M. R., Friesen, M. L., Kremer, J., Bennett, A., et al. (2017). Research priorities for harnessing plant microbiomes in sustainable agriculture. PLoS Biol. 15:e2001793. doi: 10.1371/journal.pbio.2001793

Caetano-Anollés, G., Wall, L. G., De Micheli, A. T., Macchi, E. M., Bauer, W. D., and Favelukes, G. (1988). Role of motility and chemotaxis in efficiency of nodulation by Rhizobium meliloti. Plant Physiol. 86, 1228-1235. doi: 10.1104/ pp.86.4.1228

Cai, H., Bai, Y., and Guo, C. (2018). Comparative genomics of 151 plant-associated bacteria reveal putative mechanisms underlying specific interactions between bacteria and plant hosts. Genes Genomics 40, 857-864. doi: 10.1007/s13258018-0693-1

Cammarota, G., Ianiro, G., Ahern, A., Carbone, C., Temko, A., Claesson, M. J., et al. (2020). Gut microbiome, big data and machine learning to promote precision medicine for cancer. Nat. Rev. Gastroenterol. Hepatol. 17, 635-648. doi: 10.1038/s41575-020-0327-3

Campbell, G. R. O., Reuhs, B. L., and Walker, G. C. (2002). Chronic intracellular infection of alfalfa nodules by Sinorhizobium meliloti requires correct lipopolysaccharide core. Proc. Natl. Acad. Sci. U.S.A. 99, 3938-3943. doi: 10. 1073/pnas.062425699

Canarini, A., Kaiser, C., Merchant, A., Richter, A., and Wanek, W. (2019). Root exudation of primary metabolites: mechanisms and their roles in plant responses to environmental stimuli. Front. Plant Sci. 10:157. doi: 10.3389/fpls. 2019.00157

Catroux, G., Hartmann, A., and Revellin, C. (2001). Trends in rhizobial inoculant production and use. Plant Soil 230, 21-30. doi: 10.1023/A:100477711 5628

Cavassim, M. I. A., Moeskjær, S., Moslemi, C., Fields, B., Bachmann, A., Vilhjálmsson, B. J., et al. (2020). Symbiosis genes show a unique pattern of introgression and selection within a Rhizobium leguminosarum species complex. Microb. Genomics 6:e000351. doi: 10.1099/mgen.0.000351

Chao, M. C., Abel, S., Davis, B. M., and Waldor, M. K. (2016). The design and analysis of transposon insertion sequencing experiments. Nat. Rev. Microbiol. 14, 119-128. doi: 10.1038/nrmicro.2015.7

Checcucci, A., Azzarello, E., Bazzicalupo, M., Galardini, M., Lagomarsino, A., Mancuso, S., et al. (2016). Mixed nodule infection in Sinorhizobium melilotiMedicago sativa symbiosis suggest the presence of cheating behavior. Front. Plant Sci. 7:835. doi: 10.3389/fpls.2016.00835

Checcucci, A., diCenzo, G. C., Bazzicalupo, M., and Mengoni, A. (2017). Trade, diplomacy, and warfare: the Quest for elite rhizobia inoculant strains. Front. Microbiol. 8:2207. doi: 10.3389/fmicb.2017.02207

Chhabra, S., Brazil, D., Morrissey, J., Burke, J. I., O'Gara, F., and Dowling, D. N. (2013). Characterization of mineral phosphate solubilization traits from a barley rhizosphere soil functional metagenome. Microbiologyopen 2, 717-724. doi: $10.1002 / \mathrm{mbo} 3.110$ 
Chibeba, A. M., Kyei-Boahen, S., Guimarães, M., de, F., Nogueira, M. A., and Hungria, M. (2017). Isolation, characterization and selection of indigenous Bradyrhizobium strains with outstanding symbiotic performance to increase soybean yields in Mozambique. Agric. Ecosyst. Environ. 246, 291-305. doi: 10.1016/j.agee.2017.06.017

Chomicki, G., Werner, G. D. A., West, S. A., and Kiers, E. T. (2020). Compartmentalization drives the evolution of symbiotic cooperation: compartmentalisation drives symbiosis. Philos. Trans. R. Soc. B Biol. Sci. 375:20160083.

Chung, Y. S., Lee, U., Heo, S., Silva, R. R., Na, C. I., and Kim, Y. (2020). Imagebased machine learning characterizes root nodule in soybean exposed to silicon. Front. Plant Sci. 11:520161. doi: 10.3389/fpls.2020.520161

Cole, B. J., Feltcher, M. E., Waters, R. J., Wetmore, K. M., Mucyn, T. S., Ryan, E. M., et al. (2017). Genome-wide identification of bacterial plant colonization genes. PLoS Biol. 15:1-24. doi: 10.1371/journal.pbio.2002860

Compant, S., Samad, A., Faist, H., and Sessitsch, A. (2019). A review on the plant microbiome: Ecology, functions, and emerging trends in microbial application. J. Adv. Res. 19, 29-37. doi: 10.1016/j.jare.2019.03.004

D'Haeze, W., and Holsters, M. (2004). Surface polysaccharides enable bacteria to evade plant immunity. Trends Microbiol. 12, 555-561. doi: 10.1016/j.tim.2004. 10.009

Danso, S. K. A., and Bowen, G. D. (1989). Methods of inoculation and how they influence nodulation pattern and nitrogen fixation using two contrasting strains of Bradyrhizobium japonicum. Soil Biol. Biochem. 21, 1053-1058. doi: 10.1016/0038-0717(89)90043-6

Daubech, B., Remigi, P., de Moura, G. D., Marchetti, M., Pouzet, C. C., Auriac, M. C., et al. (2017). Spatio-temporal control of mutualism in legumes helps spread symbiotic nitrogen fixation. eLife 6:e28683. doi: 10.7554/eLife.28683

Davies, B. W., and Walker, G. C. (2007). Identification of novel Sinorhizobium meliloti mutants compromised for oxidative stress protection and symbiosis. J. Bacteriol. 189, 2110-2113. doi: 10.1128/JB.01802-06

Dazzo, F. B., Truchet, G. L., Sherwood, J. E., Hrabak, E. M., Abe, M., and Pankratz, S. H. (1984). Specific phases of root hair attachment in the Rhizobium trifoliiclover symbiosis. Appl. Environ. Microbiol. 48, 1140-1150. doi: 10.1128/aem.48. 6.1140-1150.1984

De Bruijn, F. J. (1992). Use of repetitive (repetitive extragenic palindromic and enterobacterial repetitive intergeneric consensus) sequences and the polymerase chain reaction to fingerprint the genomes of Rhizobium meliloti isolates and other soil bacteria. Appl. Environ. Microbiol. 58, 2180-2187.

de Campos, S. B., Lardi, M., Gandolfi, A., Eberl, L., and Pessi, G. (2017). Mutations in Two Paraburkholderia phymatum Type VI secretion systems cause reduced fitness in interbacterial competition. Front. Microbiol. 8:2473. doi: 10.3389/ fmicb.2017.02473

del Cerro, P., Rolla-Santos, A. A., Gomes, D. F., Marks, B. B., del Rosario Espuny, M., Rodríguez-Carvajal, M. Á., et al. (2015). Opening the "black box" of nodD3, nodD4 and nodD5 genes of Rhizobium tropici strain CIAT 899. BMC Genomics 16:864. doi: 10.1186/s12864-015-2033-z

De-la-Peña, C., Lei, Z., Watson, B. S., Sumner, L. W., and Vivanco, J. M. (2008). Root-microbe communication through protein secretion. J. Biol. Chem. 283, 25247-25255. doi: 10.1074/jbc.M801967200

diCenzo, G. C., Zamani, M., Checcucci, A., Fondi, M., Griffitts, J. S., Finan, T. M., et al. (2019). Multidisciplinary approaches for studying rhizobium-legume symbioses. Can. J. Microbiol. 65, 1-33. doi: 10.1139/cjm-2018-0377

Ding, H., Yip, C. B., Geddes, B. A., Oresnik, I. J., and Hynes, M. F. (2012). Glycerol utilization by Rhizobium leguminosarum requires an $\mathrm{ABC}$ transporter and affects competition for nodulation. Microbiology 158, 1369-1378. doi: 10 . 1099/mic.0.057281-0

Drahos, D. J., Hemming, B. G., and McPherson, S. (1986). Tracking recombinant organisms in the environment: $\beta$-gaiactosidase as a selectable non-antibiotic marker for fluorescent Pseudomonas. Biotechnology 4, 439-444. doi: 10.1038/ nbt0586-439

Drew, E., Herridge, D., Ballard, R., Hara, G. O., Deaker, R., Denton, M., et al. (2012). Inoculating Legumes: A Practical Guide. Canberra: Grains Research and Development Corporation.

Drogue, B., Doré, H., Borland, S., Wisniewski-Dyé, F., and Prigent-Combaret, C. (2012). Which specificity in cooperation between phytostimulating rhizobacteria and plants? Res. Microbiol. 163, 500-510. doi: 10.1016/j.resmic. 2012.08.006
Dunham, D. H., and Baldwin, I. L. (1931). Double infection of leguminous plants with good and poor strains of rhizobia. Soil Sci. 32, 235-249. doi: 10.1097/ 00010694-193109000-00007

Duodu, S., Brophy, C., Connolly, J., and Svenning, M. M. (2009). Competitiveness of a native Rhizobium leguminosarum biovar trifolii strain for nodule occupancy is manifested during infection. Plant Soil 318, 117-126.

Duquenne, P., Chenu, C., Richard, G., and Catroux, G. (1999). Effect of carbon source supply and its location on competition between inoculated and established bacterial strains in sterile soil microcosm. FEMS Microbiol. Ecol. 29, 331-339. doi: 10.1111/j.1574-6941.1999.tb00624.x

Egamberdieva, D., Reckling, M., and Wirth, S. (2017). Biochar-based Bradyrhizobium inoculum improves growth of lupin (Lupinus angustifolius L.) under drought stress. Eur. J. Soil Biol. 78, 38-42. doi: 10.1016/j.ejsobi.2016.11.007

Epstein, B., Abou-Shanab, R. A. I., Shamseldin, A., Taylor, M. R., Guhlin, J., Burghardt, L. T., et al. (2018). Genome-wide association analyses in the model Rhizobium Ensifer meliloti. mSphere 3:e00386-18. doi: 10.1128/msphere.00 386-18

Esseling, J. J., Lhuissier, F. G. P., and Emons, A. M. C. (2003). Nod factor-induced root hair curling: continuous polar growth towards the point of Nod factor application. Plant Physiol. 132, 1982-1988. doi: 10.1104/pp.103.021634

Fagorzi, C., Bacci, G., Huang, R., Cangioli, L., Checcucci, A., Fini, M., et al. (2021). Nonadditive Transcriptomic Signatures of Genotype-by-genotype interactions during the initiation of plant-Rhizobium Symbiosis. mSystems 6:e00974-20. doi: 10.1101/2020.06.15.152710

Faiña, A., Nejati, B., and Stoy, K. (2020). Evobot: an open-source, modular, liquid handling robot for scientific experiments. Appl. Sci. 10:814. doi: 10.3390/ app 10030814

Ferguson, B. J., Indrasumunar, A., Hayashi, S., Lin, M. H., Lin, Y. H., Reid, D. E., et al. (2010). Molecular analysis of legume nodule development and autoregulation. J. Integr. Plant Biol. 52, 61-76. doi: 10.1111/j.1744-7909.2010. 00899.x

Ferguson, S., Major, A. S., Sullivan, J. T., Bourke, S. D., Kelly, S. J., Perry, B. J., et al. (2020). Rhizobium leguminosarum bv. trifolii NodD2 enhances competitive nodule colonization in the clover-rhizobium symbiosis. Appl Environ Microbiol. 86:e01268-20. doi: 10.1128/AEM.01268-20

Fields, B., Moeskjær, S., Friman, V. P., Andersen, S. U., and Young, J. P. W. (2021). MAUI-seq: metabarcoding using amplicons with unique molecular identifiers to improve error correction. Mol. Ecol. Resour. 21, 703-720. doi: 10.1111/17550998.13294

Fraysse, N., Couderc, F., and Poinsot, V. (2003). Surface polysaccharide involvement in establishing the rhizobium-legume symbiosis. Eur. J. Biochem. 270, 1365-1380. doi: 10.1046/j.1432-1033.2003.03492.x

Frederix, M., Edwards, A., Swiderska, A., Stanger, A., Karunakaran, R., Williams, A., et al. (2014). Mutation of praR in Rhizobium leguminosarum enhances root biofilms, improving nodulation competitiveness by increased expression of attachment proteins. Mol. Microbiol. 93, 464-478. doi: 10.1111/mmi.12670

Frey, S. D., and Blum, L. K. (1994). Effect of $\mathrm{pH}$ on competition for nodule occupancy by type I and type II strains of Rhizobium leguminosarum bv. phaseoli. Plant Soil 163, 157-164. doi: 10.1007/BF00007964

Friesen, M. L. (2012). Widespread fitness alignment in the legume-rhizobium symbiosis. New Phytol. 194, 1096-1111. doi: 10.1111/j.1469-8137.2012.04099.x

Fry, J., Wood, M., and Poole, P. S. (2001). Investigation of myo-inositol catabolism in Rhizobium leguminosarum bv. viciae and its effect on nodulation competitiveness. Mol. Plant Microbe Interact. 14, 1016-1025. doi: 10.1094/ MPMI.2001.14.8.1016

Gage, D. J. (2019). “Infection thread development in model legumes," in The Model Legume Medicago truncatula, ed. F. de Bruijn (New York, NY: Taylor and Francis), 579-588. doi: 10.1002/9781119409144.ch72

Galardini, M., Pini, F., Bazzicalupo, M., Biondi, E. G., and Mengoni, A. (2013). Replicon-dependent bacterial genome evolution: the case of Sinorhizobium meliloti. Genome Biol. Evol. 5, 542-558. doi: 10.1093/gbe/evt027

Gallique, M., Bouteiller, M., and Merieau, A. (2017). The Type VI secretion system: A dynamic system for bacterial communication? Front. Microbiol. 8:1454. doi: 10.3389/fmicb.2017.01454

Geddes, B. A., González, J. E., and Oresnik, I. J. (2014). Exopolysaccharide production in response to medium acidification is correlated with an increase in 
competition for nodule occupancy. Mol. Plant Microbe Interact. 27, 1307-1317. doi: 10.1094/MPMI-06-14-0168-R

Geddes, B. A., Kearsley, J. V. S., Huang, J., Zamani, M., Muhammed, Z., Sather, L., et al. (2021). Minimal gene set from Sinorhizobium (Ensifer) meliloti pSymA required for efficient symbiosis with Medicago. Proc. Natl. Acad. Sci. U.S.A. 118, e2018015118. doi: 10.1073/pnas.2018015118

Geddes, B. A., Mendoza-Suárez, M. A., and Poole, P. S. (2019a). A Bacterial Expression Vector Archive (BEVA) for flexible modular assembly of golden gate-compatible vectors. Front. Microbiol. 9:3345. doi: 10.3389/fmicb.2018. 03345

Geddes, B. A., Paramasivan, P., Joffrin, A., Thompson, A. L., Christensen, K., Jorrin, B., et al. (2019b). Engineering transkingdom signalling in plants to control gene expression in rhizosphere bacteria. Nat. Commun. 10:3430. doi: 10.1038/s41467-019-10882-x

Ghannam, R. B., and Techtmann, S. M. (2021). Machine learning applications in microbial ecology, human microbiome studies, and environmental monitoring. Comput. Struct. Biotechnol. J. 19, 1092-1107. doi: 10.1016/j.csbj.2021.01.028

Giller, K. E. (2001). Nitrogen Fixation in Tropical Cropping Systems, 2nd Edn. Wallingford: CABI. doi: 10.1079/9780851994178.0000

González, V., Bustos, P., Ramírez-Romero, M. A., Medrano-Soto, A., Salgado, H., Hernández-González, I., et al. (2003). The mosaic structure of the symbiotic plasmid of Rhizobium etli CFN42 and its relation to other symbiotic genome compartments. Genome Biol. 4:R36. doi: 10.1186/gb-2003-4-6-r36

Goodman, A. L., Wu, M., and Gordon, J. I. (2011). Identifying microbial fitness determinants by insertion sequencing using genome-wide transposon mutant libraries. Nat. Protoc. 6, 1969-1980. doi: 10.1038/nprot.2011.417

Gordon, D. M., Ryder, M. H., Heinrich, K., and Murphy, P. J. (1996). An experimental test of the rhizopine concept in Rhizobium meliloti. Appl. Environ. Microbiol. 62, 3991-3996. doi: 10.1128/aem.62.11.3991-3996.1996

Graham, P. H. (2008). "Ecology of the root-nodule bacteria of legumes," in Nitrogen-Fixing Leguminous Symbioses. Nitrogen Fixation: Origins, Applications, and Research Progress, eds M. J. Dilworth, E. K. James, and J. I. Sprent (Berlin: Springer), 22-58. doi: 10.1007/978-1-4020-3548-7_2

Graham, P. H. (1969). Selective medium for growth of Rhizobium. Appl. Microbiol. 17, 769-770. doi: 10.1128/aem.17.5.769-770.1969

Graham, P. H., and Vance, C. P. (2000). Nitrogen fixation in perspective: an overview of research and extension needs. Field Crops Res. 65, 93-106. doi: $10.1016 /$ S0378-4290(99)00080-5

Green, R. T., East, A. K., Karunakaran, R., Downie, J. A., and Poole, P. S. (2019). Transcriptomic analysis of Rhizobium leguminosarum bacteroids in determinate and indeterminate nodules. Microb. Genomics 5:e000254. doi: 10. 1099/mgen.0.000254

Gunnabo, A. H., Geurts, R., Wolde-meskel, E., Degefu, T., Giller, K. E., and van Heerwaarden, J. (2019). Genetic interaction studies reveal superior performance of Rhizobium tropici CIAT899 on a range of diverse east african common bean (Phaseolus vulgaris L.) genotypes. Appl. Environ. Microbiol. 85:e01763-19. doi: 10.1128/AEM.01763-19

Gupta, A., Gopal, M., Thomas, G. V., Manikandan, V., Gajewski, J., Thomas, G. V., et al. (2014). Whole genome sequencing and analysis of plant growth promoting bacteria isolated from the rhizosphere of plantation crops coconut, cocoa and arecanut. PLoS One 9:e104259. doi: 10.1371/journal.pone.0104259

Han, Q., Ma, Q., Chen, Y., Tian, B., Xu, L., Bai, Y., et al. (2020). Variation in rhizosphere microbial communities and its association with the symbiotic efficiency of rhizobia in soybean. ISME J. 14, 1915-1928. doi: 10.1038/s41396020-0648-9

Hansen, B. L., Pessotti, R., de, C., Fischer, M. S., Collins, A., El-Hifnawi, L., et al. (2020). Cooperation, competition, and specialized metabolism in a simplified root nodule microbiome. $m$ Bio 11:e01917-20. doi: 10.1128/mBio.01917-20

Harrison, P. W., Lower, R. P. J., Kim, N. K. D., and Young, J. P. W. (2010). Introducing the bacterial "chromid": not a chromosome, not a plasmid. Trends Microbiol. 18, 141-148. doi: 10.1016/j.tim.2009.12.010

Hartmann, M., Frey, B., Mayer, J., Mäder, P., and Widmer, F. (2015). Distinct soil microbial diversity under long-term organic and conventional farming. ISME J. 9, 1177-1194. doi: 10.1038/ismej.2014.210

Herridge, D. F., Peoples, M. B., and Boddey, R. M. (2008). Global inputs of biological nitrogen fixation in agricultural systems. Plant Soil 311, 1-18. doi: 10.1007/s11104-008-9668-3
Hill, Y., Colombi, E., Bonello, E., Haskett, T., Ramsay, J., O’Hara, G., et al. (2021). Evolution of diverse effective N2-fixing microsymbionts of Cicer arietinum following horizontal transfer of the Mesorhizobium ciceri CC1192 symbiosis integrative and conjugative element. Appl. Environ. Microbiol. 87:e02558-20. doi: 10.1128/aem.02558-20

Hirsch, P. R. (1996). Population dynamics of indigenous and genetically modified rhizobia in the field. New Phytol. 133, 159-171. doi: 10.1111/j.1469-8137.1996. tb04351.x

Hirsch, P. R., Van Montagu, M., and Johnston, A. W. B. (1980). Physical identification of bacteriocinogenic, nodulation and other plasmids in strains of Rhizobium leguminosarum. J. Gen. Microbiol. 120, 403-412. doi: 10.1099/ 00221287-120-2-403

Holland, A. A. (1966). Serologic characteristics of certain root-nodule bacteria of legumes. Antonie Van Leeuwenhoek 32, 410-418. doi: 10.1007/BF0209 7492

Hotter, G. S., and Scott, D. B. (1991). Exopolysaccharide mutants of Rhizobium loti are fully effective on a determinate nodulating host but are ineffective on an indeterminate nodulating host. J. Bacteriol. 173, 851-859. doi: 10.1128/jb.173.2. 851-859.1991

Howieson, J. G., Malden, J., Yates, R. J., and O’Hara, G. W. (2000). Techniques for the selection and development of elite inoculant strains of Rhizobium leguminosarum in southern Australia. Symbiosis 28, 33-48.

Hu, K., Li, Y., Chen, W., Chen, D., Wei, Y., Edis, R., et al. (2010). Modeling nitrate leaching and optimizing water and nitrogen management under irrigated maize in desert oases in Northwestern China. J. Environ. Qual. 39, 667-677. doi: $10.2134 /$ jeq2009.0204

Hungria, M., and Franco, A. A. (1993). Effects of high temperature on nodulation and nitrogen fixation by Phaseolus vulgaris L. Plant Soil 149, 95-102. doi: 10.1007/BF00010766

Hungria, M., and Vargas, M. A. T. (2000). Environmental factors affecting N2 fixation in grain legumes in the tropics, with an emphasis on Brazil. Field Crops Res. 65, 151-164. doi: 10.1016/S0378-4290(99)00084-2

Hungria, M., Campo, R. J., and Mendes, I. C. (2003). Benefits of inoculation of the common bean (Phaseolus vulgaris) crop with efficient and competitive Rhizobium tropici strains. Biol. Fertil. Soils 39, 88-93. doi: 10.1007/s00374-0030682-6

Hynes, M. F., and O'Connell, M. P. (1990). Host plant effect on competition among strains of Rhizobium leguminosarum. Can. J. Microbiol. 36, 864-869. doi: $10.1139 / \mathrm{m} 90-150$

Irisarri, P., Cardozo, G., Tartaglia, C., Reyno, R., Gutiérrez, P., Lattanzi, F. A., et al. (2019). Selection of competitive and efficient Rhizobia Strains for White Clover. Front. Microbiol. 10:768. doi: 10.3389/fmicb.2019.00768

Iturralde, E. T., Covelli, J. M., Alvarez, F., Pérez-Giménez, J., Arrese-Igor, C., and Lodeiro, A. R. (2019). Soybean-nodulating strains with low intrinsic competitiveness for nodulation, good symbiotic performance, and stresstolerance isolated from soybean-cropped soils in Argentina. Front. Microbiol. 10:1061. doi: $10.3389 /$ fmicb.2019.01061

Jaiswal, S. K., Mohammed, M., Ibny, F. Y. I., and Dakora, F. D. (2021). Rhizobia as a source of plant growth-promoting molecules: potential applications and possible operational mechanisms. Front. Sustain. Food Syst. 4:619676. doi: 10. 3389/fsufs.2020.619676

Janczarek, M., Jaroszuk-Ściseł, J., and Skorupska, A. (2009). Multiple copies of rosR and pssA genes enhance exopolysaccharide production, symbiotic competitiveness and clover nodulation in Rhizobium leguminosarum bv. trifolii. Antonie Van Leeuwenhoek 96, 471-486. doi: 10.1007/s10482-009-9362-3

Janczarek, M., Kutkowska, J., Piersiak, T., and Skorupska, A. (2010). Rhizobium leguminosarum bv. trifolii rosR is required for interaction with clover, biofilm formation and adaptation to the environment. BMC Microbiol. 10:284. doi: 10.1186/1471-2180-10-284

Jeckel, H., and Drescher, K. (2020). Advances and opportunities in image analysis of bacterial cells and communities. FEMS Microbiol. Rev. 062, 1-14. doi: 10. 1093/femsre/fuaa062

Ji, Z. J., Yan, H., Cui, Q. G., Wang, E. T., Chen, W. F., and Chen, W. X. (2017). Competition between rhizobia under different environmental conditions affects the nodulation of a legume. Syst. Appl. Microbiol. 40, 114-119. doi: 10.1016/j. syapm.2016.12.003

Jimenez-Zurdo, J. I., Van Dillewijn, P., Soto, M. J., De Felipe, M. R., Olivares, J., and Toro, N. (1995). Characterization of a Rhizobium meliloti proline 
dehydrogenase mutant altered in nodulation efficiency and competitiveness on alfalfa roots. Mol. Plant Microbe Interact. 8, 492-498. doi: 10.1094/MPMI-80492

Jiménez-Guerrero, I., Pérez-Montaño, F., Medina, C., Ollero, F. J., and López-Baena, F. J. (2017). The Sinorhizobium (Ensifer) fredii HH103 nodulation outer protein NopI is a determinant for efficient nodulation of soybean and cowpea plants. Appl. Environ. Microbiol. 83:16. doi: 10.1128/AEM.02770-16

Johnston, A. W. B., and Beringer, J. E. (1976). Pea root nodules containing more than one Rhizobium species. Nature 263, 502-504. doi: 10.1038/2635 $02 \mathrm{a} 0$

Jones, K. M. (2012). Increased production of the exopolysaccharide succinoglycan enhances Sinorhizobium meliloti 1021 symbiosis with the host plant Medicago truncatula. J. Bacteriol. 194, 4322-4331. doi: 10.1128/JB.00751-12

Jorrin, B., and Imperial, J. (2015). Population genomics analysis of legume host preference for specific rhizobial genotypes in the Rhizobium leguminosarum bv. viciae symbioses. Mol. Plant Microbe Interact. 28, 310-318. doi: 10.1094/MPMI09-14-0296-FI

Josey, D. P., Beynon, J. L., Johnston, A. W. B., and Beringer, J. E. (1979). Strain identification in Rhizobium using intrinsic antibiotic resistance. J. Appl. Bacteriol. 46, 343-350. doi: 10.1111/j.1365-2672.1979.tb00830.x

Juhas, M., Crook, D. W., and Hood, D. W. (2008). Type IV secretion systems: tools of bacterial horizontal gene transfer and virulence. Cell. Microbiol. 10, 2377-2386. doi: 10.1111/j.1462-5822.2008.01187.x

Kasper, S., Christoffersen, B., Soti, P., and Racelis, A. (2019). Abiotic and biotic limitations to nodulation by leguminous cover crops in south Texas. Agriculture 9:209. doi: 10.3390/agriculture9100209

Kavamura, V. N., Hayat, R., Clark, I. M., Rossmann, M., Mendes, R., Hirsch, P. R., et al. (2018). Inorganic nitrogen application affects both taxonomical and predicted functional structure of wheat rhizosphere bacterial communities. Front. Microbiol. 9:1074. doi: 10.3389/fmicb.2018.01074

Kawaharada, Y., Kelly, S., Nielsen, M. W., Hjuler, C. T., Gysel, K., Muszyński, A., et al. (2015). Receptor-mediated exopolysaccharide perception controls bacterial infection. Nature 523, 308-312. doi: 10.1038/nature14611

Kawaharada, Y., Nielsen, M. W., Kelly, S., James, E. K., Andersen, K. R., Rasmussen, S. R., et al. (2017). Differential regulation of the Epr3 receptor coordinates membrane-restricted rhizobial colonization of root nodule primordia. Nat. Commun. 8:14534. doi: 10.1038/ncomms14534

Kelly, S. J., Muszyński, A., Kawaharada, Y., Hubber, A. M., Sullivan, J. T., Sandal, N., et al. (2013). Conditional requirement for exopolysaccharide in the Mesorhizobium-Lotus symbiosis. Mol. Plant Microbe Interact. 26, 319-329. doi: 10.1094/MPMI-09-12-0227-R

Kiers, E. T., and Denison, R. F. (2008). Sanctions, cooperation, and the stability of plant-Rhizosphere Mutualisms. Annu. Rev. Ecol. Evol. Syst. 39, 215-236. doi: 10.1146/annurev.ecolsys.39.110707.173423

Kiers, E. T., Rousseau, R. A., West, S. A., and Denlson, R. F. (2003). Host sanctions and the legume-rhizobium mutualism. Nature 425, 78-81. doi: 10 . 1038/nature01931

Kinkema, M., Scott, P. T., and Gresshoff, P. M. (2006). Legume nodulation: successful symbiosis through short- and long-distance signalling. Funct. Plant Biol. 33, 707-721. doi: 10.1071/FP06056

Klogo, P. Y., Ofori, J., and Amaglo, H. (2015). Soybean (Glycine Max (L) Merill) promiscuity reaction to indigenous Bradyrhizobia inoculation In Some Ghanaian Soils. Int. J. Sci. Technol. Res. 4, 306-313.

Knights, H. E., Jorrin, B., Haskett, T. L., and Poole, P. S. (2021). Deciphering bacterial mechanisms of root colonisation. Environ. Microbiol. Rep. 13, 428444. doi: 10.1111/1758-2229.12934

Kohler, P. R. A., Zheng, J. Y., Schoffers, E., and Rossbach, S. (2010). Inositol catabolism, a key pathway in Sinorhizobium meliloti for competitive host nodulation. Appl. Environ. Microbiol. 76, 7972-7980. doi: 10.1128/AEM.01 972-10

Korenblum, E., Dong, Y., Szymanski, J., Panda, S., Jozwiak, A., Massalha, H., et al. (2020). Rhizosphere microbiome mediates systemic root metabolite exudation by root-to-root signaling. Proc. Natl. Acad. Sci. U.S.A. 117, 3874-3883. doi: 10.1073/PNAS.1912130117

Kramer, J., Özkaya, Ö., and Kümmerli, R. (2020). Bacterial siderophores in community and host interactions. Nat. Rev. Microbiol. 18, 152-163. doi: 10. 1038/s41579-019-0284-4
Krönauer, C., and Radutoiu, S. (2021). Understanding Nod factor signalling paves the way for targeted engineering in legumes and non-legumes. Curr. Opin. Plant Biol. 62:102026. doi: 10.1016/j.pbi.2021.102026

Kumar, N., Lad, G., Giuntini, E., Kaye, M. E., Udomwong, P., Shamsani, N. J., et al. (2015). Bacterial genospecies that are not ecologically coherent: population genomics of Rhizobium leguminosarum. Open Biol. 5:140133. doi: 10.1098/rsob. 140133

Kummer, R. M., and David Kuykendall, L. (1989). Symbiotic properties of amino acid auxotrophs of Bradyrhizobium japonicum. Soil Biol. Biochem. 21, 779-782. doi: 10.1016/0038-0717(89)90170-3

Kyei-Boahen, S., Savala, C. E. N., Chikoye, D., and Abaidoo, R. (2017). Growth and yield responses of cowpea to inoculation and phosphorus fertilization in different environments. Front. Plant Sci. 8:646. doi: 10.3389/fpls.2017.0 0646

Lafond, F., Greenwald, D. S., and Farmer, J. D. (2020). Can stimulating demand drive costs down? World war II as a natural experiment. Soc. Sci. Res. Netw. 1-61. doi: 10.2139/ssrn.3519913

Lagares, A., Caetano-Anolles, G., Niehaus, K., Lorenzen, J., Ljunggren, H. D., Puhler, A., et al. (1992). A Rhizobium meliloti lipopolysaccharide mutant altered in competitiveness for nodulation of alfalfa. J. Bacteriol. 174, 5941-5952. doi: 10.1128/jb.174.18.5941-5952.1992

Laguerre, G., Heulin-Gotty, K., Brunel, B., Klonowska, A., Le Quéré, A., Tillard, P., et al. (2012). Local and systemic N signaling are involved in Medicago truncatula preference for the most efficient Sinorhizobium symbiotic partners. New Phytol. 195, 437-449. doi: 10.1111/j.1469-8137.2012.04159.x

Laguerre, G., Louvrier, P., Allard, M. R., and Amarger, N. (2003). Compatibility of rhizobial genotypes within natural populations of Rhizobium leguminosarum biovar viciae for nodulation of host legumes. Appl. Environ. Microbiol. 69, 2276-2283. doi: 10.1128/AEM.69.4.2276-2283.2003

Laguerre, G., Mazurier, S. I., and Amarger, N. (1992). Plasmid profiles and restriction fragment length polymorphism of Rhizobium leguminosarum bv. viciae in field populations. FEMS Microbiol. Ecol. 101, 17-26. doi: 10.1111/j. 1574-6941.1992.tb01644.x

Lardi, M., de Campos, S. B., Purtschert, G., Eberl, L., and Pessi, G. (2017). Competition experiments for legume infection identify Burkholderia phymatum as a highly competitive $\beta$-rhizobium. Front. Microbiol. 8:1527. doi: 10.3389/fmicb.2017.01527

Laus, M. C., Logman, T. J., Lamers, G. E., Van Brussel, A. A. N., Carlson, R. W., and Kijne, J. W. (2006). A novel polar surface polysaccharide from Rhizobium leguminosarum binds host plant lectin. Mol. Microbiol. 59, 1704-1713. doi: 10.1111/j.1365-2958.2006.05057.x

Ledermann, R., Schulte, C. C. M. M., and Poole, P. S. (2021). How rhizobia adapt to the nodule environment. J. Bacteriol. 203:e0539-20. doi: 10.1128/jb.00539-20

Lin, J., Frank, M., and Reid, D. (2020). No home without hormones: How plant hormones control legume nodule organogenesis. Plant Commun. 1:100104. doi: 10.1016/j.xplc.2020.100104

Liu, D., Yang, Q., Ge, K., Hu, X., Qi, G., Du, B., et al. (2017). Promotion of iron nutrition and growth on peanut by Paenibacillus illinoisensis and Bacillus sp. strains in calcareous soil. Braz. J. Microbiol. 48, 656-670. doi: 10.1016/j.bjm. 2017.02.006

Liu, F., Hewezi, T., Lebeis, S. L., Pantalone, V., Grewal, P. S., and Staton, M. E. (2019). Soil indigenous microbiome and plant genotypes cooperatively modify soybean rhizosphere microbiome assembly. BMC Microbiol. 19:201. doi: 10. 1186/s12866-019-1572-x

Löhnis, M. P. (1930). Can Bacterium radicicola assimilate nitrogen in the absence of the host plant? Soil Sci. 29, 37-57.

López-García, S. L., Perticari, A., Piccinetti, C., Ventimiglia, L., Arias, N., De Battista, J. J., et al. (2009). In-furrow inoculation and selection for higher motility enhances the efficacy of Bradyrhizobium japonicum nodulation. Agron. J. 101, 357-363. doi: 10.2134/agronj2008.0155x

López-García, S. L., Vázquez, T. E. E. E., Favelukes, G., and Lodeiro, A. R. (2002). Rhizobial position as a main determinant in the problem of competition for nodulation in soybean. Environ. Microbiol. 4, 216-224. doi: 10.1046/j.14622920.2002.00287.x

Louvrier, P., Laguerre, G., and Amarger, N. (1996). Distribution of symbiotic genotypes in Rhizobium leguminosarum biovar viciae populations isolated directly from soils. Appl. Environ. Microbiol. 62, 4202-4205. doi: 10.1128/aem. 62.11.4202-4205.1996 
Lugtenberg, B., and Kamilova, F. (2009). Plant-growth-promoting rhizobacteria. Annu. Rev. Microbiol. 63, 541-556. doi: 10.1146/annurev.micro.62.081307. 162918

Lupwayi, N. Z., Clayton, G. W., and Rice, W. A. (2006). Rhizobial inoculants for legume crops. J. Crop Improv. 15, 97-125. doi: 10.1300/J411v15n02

Lynch, D., O’Brien, J., Welch, T., Clarke, P., Cuív, P. O., Crosa, J. H., et al. (2001). Genetic organization of the region encoding regulation, biosynthesis, and transport of rhizobactin 1021, a siderophore produced by Sinorhizobium meliloti. J. Bacteriol. 183, 2576-2585. doi: 10.1128/JB.183.8.2576-2585.2001

Ma, W., Penrose, D. M., and Glick, B. R. (2002). Strategies used by rhizobia to lower plant ethylene levels and increase nodulation. Can. J. Microbiol. 48, 947-954. doi: $10.1139 /$ w02-100

MacLean, A. M., Finan, T. M., and Sadowsky, M. J. (2007). Genomes of the symbiotic nitrogen-fixing bacteria of legumes. Plant Physiol. 144, 615-622. doi: 10.1104/pp.107.101634

Maillet, F., Fournier, J., Mendis, H. C., Tadege, M., Wen, J., Ratet, P., et al. (2020). Sinorhizobium meliloti succinylated high-molecular-weight succinoglycan and the Medicago truncatula LysM receptor-like kinase MtLYK10 participate independently in symbiotic infection. Plant J. 102, 311-326. doi: 10.1111/tpj. 14625

Marczak, M., Mazur, A., Koper, P., Żebracki, K., and Skorupska, A. (2017). Synthesis of rhizobial exopolysaccharides and their importance for symbiosis with legume plants. Genes 8:360. doi: 10.3390/genes8120360

Margaret, I., Becker, A., Blom, J., Bonilla, I., Goesmann, A., Göttfert, M., et al. (2011). Symbiotic properties and first analyses of the genomic sequence of the fast growing model strain Sinorhizobium fredii HH103 nodulating soybean. J. Biotechnol. 155, 11-19. doi: 10.1016/j.jbiotec.2011.03.016

Mauchline, T. H., Fowler, J. E., East, A. K., Sartor, A. L., Zaheer, R., Hosie, A. H. F., et al. (2006). Mapping the Sinorhizobium meliloti 1021 solute-binding proteindependent transportome. Proc. Natl. Acad. Sci. U.S.A. 103, 17933-17938. doi: 10.1073/pnas.0606673103

Marie, C., Deakin, W. J., Viprey, V., Kopciñska, J., Golinowski, W., Krishnan, H. B., et al. (2003). Characterization of Nops, nodulation outer proteins, secreted via the type III secretion system of NGR234. Mol. Plant Microbe Interact. 16, 743-751. doi: 10.1094/MPMI.2003.16.9.743

Martínez-Romero, E. (2003). Diversity of Rhizobium-Phaseolus vulgaris symbiosis: overview and perspectives. Plant Soil 252, 11-23. doi: 10.1023/A: 1024199013926

Martins Dos Santos, V. A. P., Heim, S., Moore, E. R. B., Strätz, M., and Timmis, K. N. (2004). Insights into the genomic basis of niche specificity of Pseudomonas putida KT2440. Environ. Microbiol. 6, 1264-1286. doi: 10.1111/j.1462-2920. 2004.00734.x

Massalha, H., Korenblum, E., Malitsky, S., Shapiro, O. H., and Aharoni, A. (2017). Live imaging of root-bacteria interactions in a microfluidics setup. Proc. Natl. Acad. Sci. U.S.A. 114, 4549-4554. doi: 10.1073/pnas.1618584114

May, S. N., and Bohlool, B. B. (1983). Competition Among Rhizobium leguminosarum Strains for Nodulation of Lentils (Lens esculenta). Appl. Environ. Microbiol. 45, 960-965.

Meade, J., Higgins, P., and O'Gara, F. (1985). Studies on the Inoculation and Competitiveness of a Rhizobium leguminosarum Strain in Soils Containing Indigenous Rhizobia. Appl. Environ. Microbiol. 49, 899-903. doi: 10.1128/aem. 49.4.899-903.1985

Mellor, H. Y., Glenn, A. R., Arwas, R., and Dilworth, M. J. (1987). Symbiotic and competitive properties of motility mutants of Rhizobium trifolii TA1. Arch. Microbiol. 148, 34-39. doi: 10.1007/BF00429644

Mendoza-Suárez, M. A., Geddes, B. A., Sánchez-Cañizares, C., Ramírez-González, R. H., Kirchhelle, C., Jorrin, B., et al. (2020). Optimizing Rhizobium- legume symbioses by simultaneous measurement of rhizobial competitiveness and $\mathrm{N} 2$ fixation in nodules. Proc. Natl. Acad. Sci. U.S.A. 117, 9822-9831. doi: 10.1073/ pnas. 1921225117

Mergaert, P., Uchiumi, T., Alunni, B., Evanno, G., Cheron, A., Catrice, O., et al. (2006). Eukaryotic control on bacterial cell cycle and differentiation in the Rhizobium-legume symbiosis. Proc. Natl. Acad. Sci. U.S.A. 103, 5230-5235. doi: 10.1073/pnas.0600912103

Miller, L. D., Yost, C. K., Hynes, M. F., and Alexandre, G. (2007). The major chemotaxis gene cluster of Rhizobium leguminosarum bv. viciae is essential for competitive nodulation. Mol. Microbiol. 63, 348-362. doi: 10.1111/j.1365-2958. 2006.05515.x
Mitter, E. K., Tosi, M., Obregón, D., Dunfield, K. E., and Germida, J. J. (2021). Rethinking crop nutrition in times of modern microbiology: innovative biofertilizer technologies. Front. Sustain. Food Syst. 5:606815. doi: 10.3389/fsufs. 2021.606815

Moawad, M., and Schmidt, E. L. (1987). Occurrence and nature of mixed infections in nodules of field-grown soybeans (Glycine max). Biol. Fertil. Soils 5, 112-114. doi: 10.1007/BF00257644

Moeskjær, S., Tausen, M., Andersen, S. U., and Young, J. P. W. (2020). Amplicons and isolates: Rhizobium diversity in fields under conventional and organic management. bioRxiv [Preprint]. doi: 10.1101/2020.09.22.307934

Monchgesang, S., Strehmel, N., Schmidt, S., Westphal, L., Taruttis, F., Muller, E., et al. (2016). Natural variation of root exudates in Arabidopsis thaliana-linking metabolomic and genomic data. Sci. Rep. 6:29033. doi: 10.1038/srep29033

Montañez, A., Danso, S. K. A., and Hardarson, G. (1995). The effect of temperature on nodulation and nitrogen fixation by five Bradyrhizobium japonicum strains. Appl. Soil Ecol. 2, 165-174. doi: 10.1016/0929-1393(95)00052-M

Montiel, J., Downie, J. A., Farkas, A., Bihari, P., Herczeg, R., Bálint, B., et al. (2017). Morphotype of bacteroids in different legumes correlates with the number and type of symbiotic NCR peptides. Proc. Natl. Acad. Sci. U.S.A. 114, 5041-5046. doi: 10.1073/pnas.1704217114

Montiel, J., Reid, D., Gronbaek, T. H., Benfeldt, C. M., James, E. K., Ott, T., et al. (2021). Distinct signaling routes mediate intercellular and intracellular rhizobial infection in Lotus japonicus. Plant Physiol. 185, 1131-1147. doi: 10. 1093/PLPHYS/KIAA049

Mortier, V., Holsters, M., and Goormachtig, S. (2012). Never too many? How legumes control nodule numbers. Plant Cell Environ. 35, 245-258. doi: 10.1111/ j.1365-3040.2011.02406.x

Mpepereki, S., Javaheri, F., Davis, P., and Giller, K. E. (2000). Soyabeans and sustainable agriculture Promiscuous soyabeans in southern Africa. Field Crops Res. 65, 137-149. doi: 10.1016/S0378-4290(99)00083-0

Mulas, D., Seco, V., Casquero, P. A., Velázquez, E., and González-Andrés, F. (2015). Inoculation with indigenous rhizobium strains increases yields of common bean (Phaseolus vulgaris L.) in northern Spain, although its efficiency is affected by the tillage system. Symbiosis 67, 113-124. doi: 10.1007/s13199-015-0359-6

Muller, K. E., and Denison, R. F. (2018). Resource acquisition and allocation traits in symbiotic rhizobia with implications for life-history outside of legume hosts. R. Soc. Open Sci. 5:124. doi: 10.1098/rsos.181124

Murphy, P. J., Heycke, N., and Banfalvi, Z. (1987). Genes for the catabolism and synthesis of an opine-like compound in Rhizobium meliloti are closely linked and on the Sym plasmid. Proc. Natl. Acad. Sci. U.S.A. 84, 493-497. doi: $10.1073 /$ pnas.84.2.493

Mutch, L. A., and Young, J. P. W. (2004). Diversity and specificity of Rhizobium leguminosarum biovar viciae on wild and cultivated legumes. Mol. Ecol. 13, 2435-2444. doi: 10.1111/j.1365-294X.2004.02259.x

Naeem, F. I., Ashraf, M. M., Malik, K. A., and Hafeez, F. Y. (2004). Competitiveness of introduced Rhizobium strains for nodulation in fodder legumes. Pak. J. Bot. $36,159-166$.

Nandasena, K. G., O’Hara, G. W., Tiwari, R. P., and Howieson, J. G. (2006). Rapid in situ evolution of nodulating strains for Biserrula pelecinus $\mathrm{L}$. through lateral transfer of a symbiosis island from the original mesorhizobial inoculant. Appl. Environ. Microbiol. 72, 7365-7367. doi: 10.1128/AEM.00889-06

Nandasena, K. G., O'Hara, G. W., Tiwari, R. P., Sezmis, E., and Howieson, J. G. (2007). In situ lateral transfer of symbiosis islands results in rapid evolution of diverse competitive strains of mesorhizobia suboptimal in symbiotic nitrogen fixation on the pasture legume Biserrula pelecinus L. Environ. Microbiol. 9, 2496-2511. doi: 10.1111/j.1462-2920.2007.01368.x

Navarro, A., Fos, S., Laguna, E., Durán, D., Rey, L., Rubio-Sanz, L., et al. (2014). Conservation of Endangered Lupinus mariae-josephae in Its Natural Habitat by Inoculation with Selected, Native Bradyrhizobium Strains. PLoS One 9:e102205. doi: 10.1371/journal.pone.0102205

Nelson, E. B. (2018). The seed microbiome: origins, interactions, and impacts. Plant Soil 422, 7-34. doi: 10.1007/s11104-017-3289-7

Nelson, M. S., and Sadowsky, M. J. (2015). Secretion systems and signal exchange between nitrogen-fixing rhizobia and legumes. Front. Plant Sci. 6:491. doi: $10.3389 /$ fpls.2015.00491

Nelson, M. S., Chun, C. L., and Sadowsky, M. J. (2017). Type IV effector proteins involved in the Medicago-sinorhizobium symbiosis. Mol. Plant Microbe Interact. 30, 28-34. doi: 10.1094/MPMI-10-16-0211-R 
Niehaus, K., Lagares, A., and Pühler, A. (1998). A Sinorhizobium meliloti lipopolysaccharide mutant induces effective nodules on the host plant Medicago sativa (Alfalfa) but fails to establish a symbiosis with Medicago truncatula. Mol. Plant Microbe Interact. 11, 906-914. doi: 10.1094/MPMI.1998.11.9.906

O'Callaghan, M. (2016). Microbial inoculation of seed for improved crop performance: issues and opportunities. Appl. Microbiol. Biotechnol. 100, 57295746. doi: 10.1007/s00253-016-7590-9

O'Kane, D. J., Lingle, W. L., Wampler, J. E., Legocki, M., Legocki, R. P., and Szalay, A. A. (1988). Visualization of bioluminescence as a marker of gene expression in rhizobium-infected soybean root nodules. Plant Mol. Biol. 10, 387-399. doi: 10.1007/BF00014945

Oger, P., Petit, A., and Dessaux, Y. (1997). Genetically engineered plants producing opines alter their biological environment. Nat. Biotechnol. 15, 369-372. doi: 10.1038/nbt0497-369

Okogun, J. A., and Sanginga, N. (2003). Can introduced and indigenous rhizobial strains compete for nodule formation by promiscuous soybean in the moist savanna agroecological zone of Nigeria? Biol. Fertil. Soils 38, 26-31. doi: 10. 1007/s00374-003-0611-8

Oldroyd, G. E. D. D., Murray, J. D., Poole, P. S., and Downie, J. A. (2011). The rules of engagement in the legume-rhizobial symbiosis. Annu. Rev. Genet. 45, 119-144. doi: 10.1146/annurev-genet-110410-132549

Oldroyd, G. E. D., and Downie, J. A. (2004). Calcium, kinases and nodulation signalling in legumes. Nat. Rev. Mol. Cell Biol. 5, 566-576. doi: 10.1038/ nrm1424

Onishchuk, O. P., Vorobyov, N. I., and Provorov, N. A. (2017). Nodulation competitiveness of nodule bacteria: genetic control and adaptive significance: review. Appl. Biochem. Microbiol. 53, 131-139. doi: 10.1134/S0003683817020132

Oono, R., Anderson, C. G., and Denison, R. F. (2011). Failure to fix nitrogen by non-reproductive symbiotic rhizobia triggers host sanctions that reduce fitness of their reproductive clonemates. Proc. R. Soc. B Biol. Sci. 278, 2698-2703. doi: $10.1098 /$ rspb.2010.2193

Oresnik, I. J., Pacarynuk, L. A., O’Brien, S. A. P., Yost, C. K., and Hynes, M. F. (1998). Plasmid-encoded catabolic genes in Rhizobium leguminosarum bv. trifolii: evidence for a plant-inducible rhamnose locus involved in competition for nodulation. Mol. Plant Microbe Interact. 11, 1175-1185. doi: 10.1094/MPMI. 1998.11.12.1175

Oresnik, I. J., Twelker, S., and Hynes, M. F. (1999). Cloning and characterization of a Rhizobium leguminosarum gene encoding a bacteriocin with similarities to RTX toxins. Appl. Environ. Microbiol. 65, 2833-2840. doi: 10.1128/aem.65.7. 2833-2840.1999

Parnell, J. J., Berka, R., Young, H. A., Sturino, J. M., Kang, Y., Barnhart, D. M., et al. (2016). From the lab to the farm: an industrial perspective of plant beneficial microorganisms. Front. Plant Sci 7:1110. doi: 10.3389/fpls.2016.01110

Pastor-Bueis, R., Sánchez-Cañizares, C., James, E. K., and González-Andrés, F. (2019). Formulation of a highly effective inoculant for common bean based on an autochthonous elite strain of Rhizobium leguminosarum bv. phaseoli, and Genomic-Based Insights Into Its Agronomic Performance. Front. Microbiol. 10:2724. doi: 10.3389/fmicb.2019.02724

Penmetsa, R. V., and Cook, D. R. (1997). A legume ethylene-insensitive mutant hyperinfected by its rhizobial symbiont. Science 275, 527-530. doi: 10.1126/ science.275.5299.527

Penmetsa, R. V., Frugoli, J. A., Smith, L. S., Long, S. R., and Cook, D. R. (2003). Dual genetic pathways controlling nodule number in Medicago truncatula. Plant Physiol. 131, 998-1008. doi: 10.1104/pp.015677

Peoples, M. B., Herridge, D. F., and Ladha, J. K. (1995). Biological nitrogen fixation: an efficient source of nitrogen for sustainable agricultural production? Plant Soil 174, 3-28. doi: 10.1007/BF00032239

Peralta, H., Aguilar, A., Díaz, R., Mora, Y., Martínez-Batallar, G., Salazar, E., et al. (2016). Genomic studies of nitrogen-fixing rhizobial strains from Phaseolus vulgaris seeds and nodules. BMC Genomics 17:711. doi: 10.1186/s12864-0163053-z

Pérez-Giménez, J., Iturralde, E. T., Tejerizo, G. T., Quelas, J. I., Krol, E., Borassi, C., et al. (2021). A stringent-response-defective Bradyrhizobium diazoefficiens Strain Does Not Activate the Type 3 Secretion System, Elicits an Early Plant Defense Response, and Circumvents NH4NO3- Induced Inhibition of Nodulation. Appl. Environ. Microbiol. 87:e02989-20. doi: 10.1128/AEM.029 89-20
Perret, X., Staehelin, C., and Broughton, W. J. (2000). Molecular basis of symbiotic promiscuity. Microbiol. Mol. Biol. Rev. 64, 180-201. doi: 10.1128/MMBR.64.1. 180-201.2000

Perry, B. J., and Yost, C. K. (2014). Construction of a mariner-based transposon vector for use in insertion sequence mutagenesis in selected members of the Rhizobiaceae. BMC Microbiol. 14:298. doi: 10.1186/s12866-014-0298-z

Persmark, M., Pittman, P., Buyer, J. S., Schwyn, B., Gill, P. R., and Neilands, J. B. (1993). Isolation and Structure of Rhizobactin 1021, a Siderophore from the Alfalfa Symbiont Rhizobium meliloti 1021. J. Am. Chem. Soc. 115, 3950-3956. doi: 10.1021/ja00063a014

Philippot, L., Raaijmakers, J. M., Lemanceau, P., and Van Der Putten, W. H. (2013). Going back to the roots: the microbial ecology of the rhizosphere. Nat. Rev. Microbiol. 11, 789-799. doi: 10.1038/nrmicro3109

Pini, F., East, A. K., Appia-Ayme, C., Tomek, J., Karunakaran, R., Mendoza-Suárez, M., et al. (2017). Bacterial biosensors for in vivo spatiotemporal mapping of root secretion. Plant Physiol. 174, 1289-1306. doi: 10.1104/pp.16.01302

Pobigaylo, N., Szymczak, S., Nattkemper, T. W., and Becker, A. (2008). Identification of genes relevant to symbiosis and competitiveness in Sinorhizobium meliloti using signature-tagged mutants. Mol. Plant Microbe Interact. 21, 219-231. doi: 10.1094/MPMI-21-2-0219

Poole, P. (2017). Shining a light on the dark world of plant root-microbe interactions. Proc. Natl. Acad. Sci. U.S.A. 114, 4281-4283. doi: 10.1073/pnas. 1703800114

Poole, P., Ramachandran, V., and Terpolilli, J. (2018). Rhizobia: from saprophytes to endosymbionts. Nat. Rev. Microbiol. 16, 291-303. doi: 10.1038/nrmicro. 2017.171

Queiroux, C., Washburn, B. K., Davis, O. M., Stewart, J., Brewer, T. E., Lyons, M. R., et al. (2012). A comparative genomics screen identifies a Sinorhizobium meliloti 1021 sodM-like gene strongly expressed within host plant nodules. BMC Microbiol. 12:74. doi: 10.1186/1471-2180-12-74

Rachwał, K., Boguszewska, A., Kopcińska, J., Karaś, M., Tchórzewski, M., and Janczarek, M. (2016). The Regulatory Protein RosR Affects Rhizobium leguminosarum bv. trifolii Protein Profiles, Cell Surface Properties, and Symbiosis with Clover. Front. Microbiol. 7:1302. doi: 10.3389/fmicb.2016.01302

Rae, A. E., Rolland, V., White, R. G., and Mathesius, U. (2021). New methods for confocal imaging of infection threads in crop and model legumes. Plant Methods 17:24. doi: 10.1186/s13007-021-00725-6

Raina, J. B., Fernandez, V., Lambert, B., Stocker, R., and Seymour, J. R. (2019). The role of microbial motility and chemotaxis in symbiosis. Nat. Rev. Microbiol. 17, 284-294. doi: 10.1038/s41579-019-0182-9

Rao, D. L. N., Giller, K. E., Yeo, A. R., and Flowers, T. J. (2002). The effects of salinity and sodicity upon nodulation and nitrogen fixation in chickpea (Cicer arietinum). Ann. Bot. 89, 563-570. doi: 10.1093/aob/mcf097

Ratcliff, W. C., Kadam, S. V., and Denison, R. F. (2008). Poly-3-hydroxybutyrate (PHB) supports survival and reproduction in starving rhizobia. FEMS Microbiol. Ecol. 65, 391-399. doi: 10.1111/j.1574-6941.2008.00544.x

Rathi, S., Tak, N., Bissa, G., Chouhan, B., Ojha, A., Adhikari, D., et al. (2018). Selection of Bradyrhizobium or Ensifer symbionts by the native Indian caesalpinioid legume Chamaecrista pumila depends on soil $\mathrm{pH}$ and other edaphic and climatic factors. FEMS Microbiol. Ecol. 94:fiy180.

Regus, J. U., Quides, K. W., O’Neill, M. R., Suzuki, R., Savory, E. A., Chang, J. H., et al. (2017). Cell autonomous sanctions in legumes target ineffective rhizobia in nodules with mixed infections. Am. J. Bot. 104, 1299-1312. doi: 10.3732/ajb.1700165

Reid, D. E., Ferguson, B. J., Hayashi, S., Lin, Y. H., and Gresshoff, P. M. (2011). Molecular mechanisms controlling legume autoregulation of nodulation. Ann. Bot. 108, 789-795. doi: 10.1093/aob/mcr205

Reid, T. E., Kavamura, V. N., Abadie, M., Torres-Ballesteros, A., Pawlett, M., Clark, I. M., et al. (2021). Inorganic chemical fertilizer application to wheat reduces the abundance of putative plant growth-promoting Rhizobacteria. Front. Microbiol. 12:642587. doi: 10.3389/fmicb.2021.642587

Riaz, U., Mehdi, S. M., Iqbal, S., Khalid, H. I., Qadir, A. A., Anum, W., et al. (2020). "Bio-fertilizers: eco-friendly approach for plant and soil environment," in Bioremediation and Biotechnology: Sustainable Approaches to Pollution Degradation, eds K. Hakeem, R. Bhat, and H. Qadri (Berlin: Springer), 189-213. doi: 10.1007/978-3-030-35691-0_9

Rivas, R., Laranjo, M., Mateos, P. F., Oliveira, S., Martínez-Molina, E., and Velázquez, E. (2007). Strains of Mesorhizobium amorphae and Mesorhizobium 
tianshanense, carrying symbiotic genes of common chickpea endosymbiotic species, constitute a novel biovar (ciceri) capable of nodulating Cicer arietinum. Lett. Appl. Microbiol. 44, 412-418. doi: 10.1111/j.1472-765X.2006.02086.x

Robinson, D. G., Chen, W., Storey, J. D., and Gresham, D. (2014). Design and analysis of bar-seq experiments. G3 4, 11-18. doi: 10.1534/g3.113.008565

Robleto, E. A., Kmiecik, K., Oplinger, E. S., Nienhuis, J., and Triplett, E. W. (1998). Trifolitoxin production increases nodulation competitiveness of Rhizobium etli CE3 under agricultural conditions. Appl. Environ. Microbiol. 64:2630. doi: 10. 1128/aem.64.7.2630-2633.1998

Rodríguez-Echeverría, S., Pérez-Fernández, M. A., Vlaar, S., and Finnan, T. (2003). Analysis of the legume-rhizobia symbiosis in shrubs from central western Spain. J. Appl. Microbiol. 95, 1367-1374. doi: 10.1046/j.1365-2672.2003.02118.x

Rodríguez-Navarro, D. N., Dardanelli, M. S., and Ruíz-Saínz, J. E. (2007). Attachment of bacteria to the roots of higher plants. FEMS Microbiol. Lett. 272, 127-136. doi: 10.1111/j.1574-6968.2007.00761.x

Romero-Jiménez, L., Rodríguez-Carbonell, D., Gallegos, M. T., Sanjuán, J., and Pérez-Mendoza, D. (2015). Mini-Tn7 vectors for stable expression of diguanylate cyclase PleD* in Gram-negative bacteria. BMC Microbiol. 15:190. doi: 10.1186/s12866-015-0521-6

Ronson, C. W., and Lowther, W. L. (1995). Issues affecting the competitiveness of white clover rhizobia in New Zealand pastures. Agron. Soc. New Zeal. 5, 87-90.

Rosenblueth, M., Hynes, M. F., and Martínez-Romero, E. (1998). Rhizobium tropici teu genes involved in specific uptake of Phaseolus vulgaris bean-exudate compounds. Mol. Gen. Genet. 258, 587-598. doi: 10.1007/s004380050772

Roskothen, P. (1989). Genetic effects on Host x Strain Interaction in the Symbiosis of Vicia faba and Rhizobium leguminosarum. Plant Breed. 102, 122-132. doi: 10.1111/j.1439-0523.1989.tb00325.x

Russo, D. M., Williams, A., Edwards, A., Posadas, D. M., Finnie, C., Dankert, M., et al. (2006). Proteins exported via the PrsD-PrsE type I secretion system and the acidic exopolysaccharide are involved in biofilm formation by Rhizobium leguminosarum. J. Bacteriol. 188, 4474-4486. doi: 10.1128/JB.00246-06

Rynne, F. G., Glenn, A. R., and Dilworth, M. J. (1994). Effect of mutations in aromatic catabolism on the persistence and competitiveness of Rhizobium leguminosarum bv. trifolii. Soil Biol. Biochem. 26, 703-710. doi: 10.1016/00380717(94)90262-3

Saad, M. M., Eida, A. A., Hirt, H., and Doerner, P. (2020). Tailoring plant-associated microbial inoculants in agriculture: a roadmap for successful application. J. Exp. Bot. 71, 3878-3901. doi: 10.1093/jxb/eraa111

Sachs, J. L., Ehinger, M. O., and Simms, E. L. (2010). Origins of cheating and loss of symbiosis in wild Bradyrhizobium. J. Evol. Biol. 23, 1075-1089. doi: 10.1111/j.1420-9101.2010.01980.x

Salas, M. E., Lozano, M. J., López, J. L., Draghi, W. O., Serrania, J., Torres Tejerizo, G. A., et al. (2017). Specificity traits consistent with legume-rhizobia coevolution displayed by Ensifer meliloti rhizosphere colonization. Environ. Microbiol. 19, 3423-3438. doi: 10.1111/1462-2920.13820

Salinero-Lanzarote, A., Pacheco-Moreno, A., Domingo-Serrano, L., Durán, D., Ormeño-Orrillo, E., Martínez-Romero, E., et al. (2019). The Type VI secretion system of Rhizobium etli Mim1 has a positive effect in symbiosis. FEMS Microbiol. Ecol. 95:fiz054. doi: 10.1093/femsec/fiz054

Sánchez-Cañizares, C., and Palacios, J. (2013). Construction of a marker system for the evaluation of competitiveness for legume nodulation in Rhizobium strains. J. Microbiol. Methods 92, 246-249. doi: 10.1016/j.mimet.2012.12.022

Santos, M. S., Nogueira, M. A., and Hungria, M. (2019). Microbial inoculants: reviewing the past, discussing the present and previewing an outstanding future for the use of beneficial bacteria in agriculture. AMB Express 9:205. doi: 10.1186/ s13568-019-0932-0

Santos, R., Hérouart, D., Sigaud, S., Touati, D., and Puppo, A. (2001). Oxidative burst in alfalfa-Sinorhizobium meliloti symbiotic interaction. Mol. Plant Microbe Interact. 14, 86-89. doi: 10.1094/MPMI.2001.14.1.86

Schlaeppi, K., and Bulgarelli, D. (2015). The plant microbiome at work. Mol. Plant Microbe Interact. 28, 212-217. doi: 10.1094/MPMI-10-14-0334-FI

Schmidt, O., Hawkes, A., Gambhir, A., and Staffell, I. (2017). The future cost of electrical energy storage based on experience rates. Nat. Energy 2:17110. doi: 10.1038/nenergy.2017.110

Schofield, P. R., Gibson, A. H., Dudman, W. F., and Watson, J. M. (1987). Evidence for genetic exchange and recombination of Rhizobium Symbiotic plasmids in a soil population. Appl. Environ. Microbiol. 53, 2942-2947. doi: 10.1128/aem.53. 12.2942-2947.1987
Schripsema, J., de Rudder, K. E., van Vliet, T. B., Lankhorst, P. P., de Vroom, E., Kijne, J. W., et al. (1996). Bacteriocin small of Rhizobium leguminosarum belongs to the class of $\mathrm{N}$-acyl-L-homoserine lactone molecules, known as autoinducers and as quorum sensing co-transcription factors. J. Bacteriol. 178, 366-371. doi: 10.1128/JB.178.2.366-371.1996

Schwarz, S., Hood, R. D., and Mougous, J. D. (2010). What is type VI secretion doing in all those bugs? Trends Microbiol. 18, 531-537. doi: 10.1016/j.tim.2010. 09.001

Schwinghamer, E. A., and Belkengren, R. P. (1968). Inhibition of rhizobia by a strain of Rhizobium trifolii: some properties of the antibiotic and of the strain. Arch. Mikrobiol. 64, 130-145. doi: 10.1007/BF00406972

Sessitsch, A., Howieson, J. G., Perret, X., Antoun, H., and Martínez-Romero, E. (2002). Advances in Rhizobium research. CRC Crit. Rev. Plant Sci. 21, 323-378. doi: 10.1080/0735-260291044278

Sessitsch, A., Wilson, K., Akkermans, A., and de Vos, W. (1996). Simultaneous detection of different Rhizobium strains marked with either the Escherichia coli gusA gene or the Pyrococcus furiosus celB gene. Appl. Environ. Microbiol. 62, 4191-4194.

Shamseldin, A., and Velázquez, E. (2020). The promiscuity of Phaseolus vulgaris L. (common bean) for nodulation with rhizobia: a review. World J. Microbiol. Biotechnol. 36:63. doi: 10.1007/s11274-020-02839-w

Sharypova, L. A., Niehaus, K., Scheidle, H., Holst, O., and Becker, A. (2003). Sinorhizobium meliloti acpXL mutant lacks the C28 hydroxylated fatty acid moiety of lipid $\mathrm{A}$ and does not express a slow migrating form of lipopolysaccharide. J. Biol. Chem. 278, 12946-12954. doi: 10.1074/jbc. M209389200

Siefert, A., Zillig, K. W., Friesen, M. L., and Strauss, S. Y. (2018). Soil microbial communities alter conspecific and congeneric competition consistent with patterns of field coexistence in three Trifolium congeners. J. Ecol. 106, 18761891. doi: 10.1111/1365-2745.13042

Simonsen, A. K., DInnage, R., Barrett, L. G., Prober, S. M., and Thrall, P. H. (2017). Symbiosis limits establishment of legumes outside their native range at a global scale. Nat. Commun. 8:14790. doi: 10.1038/ncomms 14790

Slattery, J., and Pearce, D. (2002). "Development of Elite Inoculant Rhizobium Strains in Southeastern Australia," in Inoculants and Nitrogen Fixation of Legumes in Vietnam, ed. D. Herridge (Jakarta: ACIAR), 86-94.

Smit, G., Logman, T. J., Boerrigter, M. E., Kijne, J. W., and Lugtenberg, B. J. (1989). Purification and partial characterization of the Rhizobium leguminosarum biovar viciae $\mathrm{Ca}^{2+}$-dependent adhesin, which mediates the first step in attachment of cells of the family Rhizobiaceae to plant root hair tips. J. Bacteriol. 171, 4054-4062. doi: 10.1128/jb.171.7.4054-4062.1989

Smit, G., Swart, S., Lugtenberg, B. J., and Kijne, J. W. (1992). Molecular mechanisms of attachment of Rhizobium bacteria to plant roots. Mol. Microbiol. 6, 2897-2903.

Song, L., Hou, L., Zhang, Y., Li, Z., Wang, W., and Sun, Q. (2020). Regular biochar and bacteria-inoculated biochar alter the composition of the microbial community in the soil of a Chinese fir plantation. Forests 11:951. doi: 10.3390/ f11090951

Sotelo, M., Irisarri, P., Lorite, M. J., Casaretto, E., Rebuffo, M., Sanjuán, J., et al. (2011). Diversity of rhizobia nodulating Lotus corniculatus grown in northern and southern regions of Uruguay. Appl. Soil Ecol. 49, 197-207. doi: 10.1016/j. apsoil.2011.05.005

Soumare, A., Diedhiou, A. G., Thuita, M., Hafidi, M., Ouhdouch, Y., Gopalakrishnan, S., et al. (2020). Exploiting biological nitrogen fixation: a route towards a sustainable agriculture. Plants 9:1011. doi: 10.3390/plants9081011

Sprent, J. I. (2008). "Evolution and diversity of legume symbiosis," in Nitrogenfixing Leguminous Symbioses Nitrogen Fixation: Origins, Applications, and Research Progress, eds M. Dilworth, E. James, J. Sprent, and W. Newton (Berlin: Springer), 1-21. doi: 10.1007/978-1-4020-3548-7_1

Stacey, G., So, J. S., Roth, L. E., Lakshmi, B. S. K., and Carlson, R. W. (1991). A lipopolysaccharide mutant of Bradyrhizobium japonicum that uncouples plant from bacterial differentiation. Mol. Plant Microbe Interact. 4, 332-340. doi: 10.1094/MPMI-4-332

Streit, W., Kosch, K., and Werner, D. (1992). Nodulation competitiveness of Rhizobium leguminosarum bv. phaseoli and Rhizobium tropici strains measured by glucuronidase (gus) gene fusion. Biol. Fertil. Soils 14, 140-144. doi: 10.1007/ BF00336264 
Stuurman, N., Pacios Bras, C., Schlaman, H. R. M., Wijfjes, A. H. M., Bloemberg, G., and Spaink, H. P. (2000). Use of green fluorescent protein color variants expressed on stable broad-host-range vectors to visualize rhizobia interacting with plants. Mol. Plant Microbe Interact. 13, 1163-1169. doi: 10.1094/MPMI. 2000.13.11.1163

Sugawara, M., Okazaki, S., Nukui, N., Ezura, H., Mitsui, H., and Minamisawa, K. (2006). Rhizobitoxine modulates plant-microbe interactions by ethylene inhibition. Biotechnol. Adv. 24, 382-388. doi: 10.1016/j.biotechadv.2006.01.004

Sullivan, J. T., and Ronson, C. W. (1998). Evolution of rhizobia by acquisition of a 500-kb symbiosis island that integrates into a phe-tRNA gene. Proc. Natl. Acad. Sci. U.S.A. 95, 5145-5149. doi: 10.1073/pnas.95.9.5145

Sullivan, J. T., Patrick, H. N., Lowther, W. L., Scott, D. B., and Ronson, C. W. (1995). Nodulating strains of Rhizobium loti arise through chromosomal symbiotic gene transfer in the environment. Proc. Natl. Acad. Sci. U.S.A. 92, 8985-8989. doi: 10.1073 /pnas. 92.19 .8985

Taté, R., Riccio, A., Caputo, E., Cermola, M., Favre, R., and Patriarca, E. J. (1999). The Rhizobium etli $\operatorname{trp} B$ gene is essential for an effective symbiotic interaction with Phaseolus vulgaris. Mol. Plant Microbe Interact. 12, 926-933. doi: 10.1094/ MPMI.1999.12.10.926

Tausen, M., Clausen, M., Moeskjær, S., Shihavuddin, A. S. M., Dahl, A. B., Janss, L., et al. (2020). Greenotyper: image-based plant phenotyping using distributed computing and deep learning. Front. Plant Sci. 11:1181. doi: 10.3389/fpls.2020. 01181

Temprano, F. J., Albareda, M., Camacho, M., Daza, A., Santamaría, C., and Rodríguez-Navarro, D. N. (2002). Survival of several Rhizobium/Bradyrhizobium strains on different inoculant formulations and inoculated seeds. Int. Microbiol. 5, 81-86. doi: 10.1007/s10123-0020067-y

Thrall, P. H., Millsom, D. A., Jeavons, A. C., Waayers, M., Harvey, G. R., Bagnall, D. J., et al. (2005). Seed inoculation with effective root-nodule bacteria enhances revegetation success. J. Appl. Ecol. 42, 740-751. doi: 10.1111/j.1365-2664.2005. 01058.x

Timmers, A. C. J. J., Soupène, E., Auriac, M.-C. C., de Billy, F., Vasse, J., Boistard, P., et al. (2000). Saprophytic intracellular Rhizobia in Alfalfa Nodules. Mol. Plant Microbe Interact. 13, 1204-1213. doi: 10.1094/MPMI.2000.13.11.1204

Triplett, E. W., and Barta, T. M. (1987). Trifolitoxin Production and Nodulation Are Necessary for the Expression of Superior Nodulation Competitiveness by Rhizobium leguminosarum bv. trifolii Strain T24 on Clover. Plant Physiol. 85, 335-342. doi: 10.1104/pp.85. 2.335

Triplett, E. W., and Sadowsky, M. J. (1992). Genetics of competition for nodulation of legumes. Annu. Rev. Microbiol. 46, 399-428. doi: 10.1146/annurev.micro.46. 1.399

Trivedi, P., Leach, J. E., Tringe, S. G., Sa, T., and Singh, B. K. (2020). Plantmicrobiome interactions: from community assembly to plant health. Nat. Rev. Microbiol. 18, 607-621. doi: 10.1038/s41579-020-0412-1

Turgeon, B. G., and Bauer, W. D. (1985). Ultrastructure of infection-thread development during the infection of soybean by Rhizobium japonicum. Planta 163, 328-349. doi: 10.1007/BF00395142

Turner, T. R., James, E. K., and Poole, P. S. (2013). The plant microbiome. Genome Biol. 14:209. doi: 10.1186/gb-2013-14-6-209

Udvardi, M., and Poole, P. S. (2013). Transport and metabolism in legume-rhizobia symbioses. Annu. Rev. Plant Biol. 64, 781-805. doi: 10.1146/annurev-arplant050312-120235

Vanderlinde, E. M., Hynes, M. F., and Yost, C. K. (2014). Homoserine catabolism by Rhizobium leguminosarum bv. viciae 3841 requires a plasmid-borne gene cluster that also affects competitiveness for nodulation. Environ. Microbiol. 16, 205-217. doi: 10.1111/1462-2920.12196

Venter, A. P., Twelker, S., Oresnik, I. J., and Hynes, M. F. (2001). Analysis of the genetic region encoding a novel rhizobiocin from Rhizobium leguminosarum bv. viciae strain 306. Can. J. Microbiol. 47, 495-502. doi: 10.1139/cjm-47-6-495

Vessey, J. K. (2003). Plant growth promoting rhizobacteria as biofertilizers. Plant Soil 255, 571-586. doi: 10.1023/A:1026037216893

Vlassak, K. M., and Vanderleyden, J. (1997). Factors influencing nodule occupancy by inoculant Rhizobia. CRC Crit. Rev. Plant Sci. 16, 163-229. doi: 10.1080/ 07352689709701948
Vuong, H. B., Thrall, P. H., and Barrett, L. G. (2017). Host species and environmental variation can influence rhizobial community composition. J. Ecol. 105, 540-548. doi: 10.1111/1365-2745.12687

Weese, D. J., Heath, K. D., Dentinger, B. T. M., and Lau, J. A. (2015). Long-term nitrogen addition causes the evolution of less-cooperative mutualists. Evolution 69, 631-642. doi: 10.1111/evo.12594

Werner, D., and Newton, W. E. (2005). Nitrogen Fixation in Agriculture, Forestry, Ecology, and the Environment, eds D. Werner and W. E. Newton (Berlin: Springer). doi: 10.1007/1-4020-3544-6

West, S. A., Kiers, E. T., Simms, E. L., and Denison, R. F. (2002). Sanctions and mutualism stability: Why do rhizobia fix nitrogen? Proc. R. Soc. B Biol. Sci. 269, 685-694. doi: 10.1098/rspb.2001.1878

Westhoek, A., Clark, L. J., Culbert, M., Dalchau, N., Griffiths, M., Jorrin, B., et al. (2021). Conditional sanctioning in a legume-Rhizobium mutualism. Proc. Natl. Acad. Sci. U.S.A. 118:e2025760118. doi: 10.1073/pnas.2025760118

Wetmore, K. M., Price, M. N., Waters, R. J., Lamson, J. S., He, J., Hoover, C. A., et al. (2015). Rapid quantification of mutant fitness in diverse bacteria by sequencing randomly bar-coded transposons. MBio 6:e00306-15. doi: 10.1128/mBio.0030615

Wheatley, R. M., and Poole, P. S. (2018). Mechanisms of bacterial attachment to roots. FEMS Microbiol. Rev. 42, 448-461. doi: 10.1093/femsre/fuy014

Wheatley, R. M., Ford, B. L., Li, L., Aroney, S. T. N., Knights, H. E., Ledermann, R., et al. (2020). Lifestyle adaptations of Rhizobium from rhizosphere to symbiosis. Proc. Natl. Acad. Sci. U.S.A. 117, 23823-23834. doi: 10.1073/pnas.2009094117

Wielbo, J., Kuske, J., Marek-Kozaczuk, M., and Skorupska, A. (2010). The competition between Rhizobium leguminosarum bv. viciae strains progresses until late stages of symbiosis. Plant Soil 337, 125-135. doi: 10.1007/s11104-0100510-3

Williams, A., Wilkinson, A., Krehenbrink, M., Russo, D. M., Zorreguieta, A., and Downie, J. A. (2008). Glucomannan-mediated attachment of Rhizobium leguminosarum to pea root hairs is required for competitive nodule infection. J. Bacteriol. 190, 4706-4715. doi: 10.1128/JB.01694-07

Wilson, K. J., Peoples, M. B., and Jefferson, R. A. (1995a). New techniques for studying competition by Rhizobia and for assessing nitrogen fixation in the field. Plant Soil 174, 241-253. doi: 10.1007/BF00032250

Wilson, K. J., Sessitsch, A., Corbo, J. C., Giller, K. E., Akkermans, A. D. L., and Jefferson, R. A. (1995b). $\beta$-Glucuronidase (GUS) transposons for ecological and genetic studies of rhizobia and other Gram-negative bacteria. Microbiology 141, 1691-1705. doi: 10.1099/13500872-141-7-1691

Wong, B. G., Mancuso, C. P., Kiriakov, S., Bashor, C. J., and Khalil, A. S. (2018). Precise, automated control of conditions for high-throughput growth of yeast and bacteria with eVOLVER. Nat. Biotechnol. 36, 614-623. doi: 10.1038/nbt. 4151

Xie, F., Williams, A., Edwards, A., and Downie, J. A. (2012). A plant arabinogalactan-like glycoprotein promotes a novel type of polar surface attachment by Rhizobium leguminosarum. Mol. Plant Microbe Interact. 25, 250-258. doi: 10.1094/MPMI-08-11-0211

Yates, R. J., Howieson, J. G., Reeve, W. G., and O'Hara, G. W. (2011). A reappraisal of the biology and terminology describing rhizobial strain success in nodule occupancy of legumes in agriculture. Plant Soil 348, 255-267. doi: 10.1007/s11104-011-0971-z

Young, J. P. W., and Wexler, M. (1988). Sym plasmid and chromosomal genotypes are correlated in field populations of Rhizobium leguminosarum. Microbiology 134, 2731-2739. doi: 10.1099/00221287-134-10-2731

Zahran, H. H. (1999). Rhizobium-legume symbiosis and nitrogen fixation under severe conditions and in an arid climate. Microbiol. Mol. Biol. Rev. 63, 968-989.

Zgadzaj, R., Garrido-Oter, R., Jensen, D. B., Koprivova, A., Schulze-Lefert, P., and Radutoiu, S. (2016). Root nodule symbiosis in Lotus japonicus drives the establishment of distinctive rhizosphere, root, and nodule bacterial communities. Proc. Natl. Acad. Sci. U.S.A. 113, E7996-E8005. doi: 10.1073/ pnas. 1616564113

Zhalnina, K., Louie, K. B., Hao, Z., Mansoori, N., da Rocha, U. N., Shi, S., et al. (2018). Dynamic root exudate chemistry and microbial substrate preferences drive patterns in rhizosphere microbial community assembly. Nat. Microbiol. 34, 470-480. doi: 10.1038/s41564-018-0129-3 
Zheng, H., Mao, Y., Teng, J., Zhu, Q., Ling, J., and Zhong, Z. (2015). Flagellardependent motility in Mesorhizobium tianshanense is involved in the early stage of plant host interaction: study of an flgE mutant. Curr. Microbiol. 70, 219-227. doi: 10.1007/s00284-014-0701-x

Zhu, S., Vivanco, J. M., and Manter, D. K. (2016). Nitrogen fertilizer rate affects root exudation, the rhizosphere microbiome and nitrogen-use-efficiency of maize. Appl. Soil Ecol. 107, 324-333. doi: 10.1016/j.apsoil.2016.07.009

Zvinavashe, A. T., Lim, E., Sun, H., and Marelli, B. (2019). A bioinspired approach to engineer seed microenvironment to boost germination and mitigate soil salinity. Proc. Natl. Acad. Sci. U.S.A. 116, 25555-25561. doi: 10.1073/pnas. 1915902116

Conflict of Interest: The authors declare that the research was conducted in the absence of any commercial or financial relationships that could be construed as a potential conflict of interest.
Publisher's Note: All claims expressed in this article are solely those of the authors and do not necessarily represent those of their affiliated organizations, or those of the publisher, the editors and the reviewers. Any product that may be evaluated in this article, or claim that may be made by its manufacturer, is not guaranteed or endorsed by the publisher.

Copyright (c) 2021 Mendoza-Suárez, Andersen, Poole and SánchezCañizares. This is an open-access article distributed under the terms of the Creative Commons Attribution License (CC BY). The use, distribution or reproduction in other forums is permitted, provided the original author(s) and the copyright owner(s) are credited and that the original publication in this journal is cited, in accordance with accepted academic practice. No use, distribution or reproduction is permitted which does not comply with these terms. 